\title{
MINERALOGIA E COMPOSIÇÃO QUIMICA DA FRAÇÃO ARGILOSA DOS SEDIMENTOS DO FUNDO DA BAIA DE TODOS OS SANTOS, BAHIA
}

\author{
GERALDO DA SILVA VILAS BOAS* e ABÍlIO CARLOS DA SILVA \\ PINTO BITTENCOURT**
}

\begin{abstract}
The distribution of the clay minerals of the argillaceous fraction of the bottom sediments of Todos os Santos Bay reflects the climatic condition, the constitution of the rocks, and the weathering products of the region. Based on the distribution and on the source of the clay minerals, the area can be divided into three parts: a) Northern region, of low energy where the argillaceous sedimentation is more intense and derives mainly from the erosion of the nearby sedimentary rocks. Kaolinite predominates slightly over illite, whereas the montmorillonite is present in subordinated amounts; b) Southern region of relatively high energy. The argillaceous sedimentation is rare and influenced by the material brought from the oceanic regions. Kaolinite predominates in excess of $50 \%$ of the total amount of the clay minerals; c) Region of influence of the Paraguaçu River. Kaolinite is the main clay mineral, and montmorillonite predominates over illite.

The mineralogy of the clay minerals controls the distribution of $\mathrm{S}_{\mathrm{i}}, \mathrm{Al}, \mathrm{K}$, and $\mathrm{Mg}$. The distribution of $\mathrm{Ca}$ and $\mathrm{Sr}$ is related to the fine-grained biodetritic material present in the clay fraction. The relatively high content of Fe results from the intense action of the chemical weathering in the source area. The elements $\mathrm{Cu}, \mathrm{Ni}, \mathrm{Cr}$, and $\mathrm{Zn}$ occur adsorbed on the surface of the clay particles. Relatively high concentrations of $\mathrm{Zn}$ in some areas probably result from the pollution by industrial wastes.
\end{abstract}

INTRODUÇÃO Estudos visando a criação de modelos de sedimentação, a partir de ambientes atuais, têm tomado grande impulso, como uma necessidade fundamental para a interpretação de ambientes do passado. No que diz respeito às regiões de clima temperado, numerosos têm sido os trabalhos realizados, o que não se observa em relação aos trópicos.

A Baía de Todos os Santos (Fig. 1), um dos maiores acidentes hidrográficos da costa brasileira, tem sido razoavelmente estudada, nesta década. Bittencourt et al. (1976) analisaram os principais trabalhos realizados até então. Esses trabalhos, na sua quase totalidade, estão restritos ou à análise dos aspectos texturais dos sedimentos, de um modo geral, ou à caracterização dos componentes biogênicos do fundo.

Bittencourt et al. (1976) mapearam quatro tipos de fácies sedimentares no fundo da Baía de Todos os Santos: a) fácies de lama, com mais de $50 \%$ de argila; b) fácies de biodetritos, com mais de $50 \%$ de componentes biogênicos; c) fácies de areia quartzosa, com mais de $50 \%$ de quartzo e d) fácies mista, caracterizada pela mistura, em diferentes proporções, de lama, biodetritos e quartzo. Segundo os referidos autores, a sedimentação atual é essencialmente argilosa e se processa principalmente na sua metade norte. Esse material, por estar sendo depositado em equilíbrio com as condições ambientais atuais, foi escolhido para a análise do presente trabalho, na tentativa de oferecer uma contribuição para o conhecimento de um ambiente marinho de baía, recente, localizado nos trópicos, através do estudo da composição mineralógica e química da fração inferior a 2 micra, bem como da sua distribuição e origem.

O contorno da Baía de Todos os Santos apresenta um aspecto recortado, sendo a topografia dos terrenos circundantes relativamente plana, com exceção da costa a sudeste, defronte ao Canal de Itaparica-Salvador e, do lado oeste, defronte ao Canal de Itaparica, onde o relevo é mais acentuado.

A maior parte da baía apresenta uma topografia de fundo relativamente plana, com profundidades entre 2 e $10 \mathrm{~m}$. Profundidades maiores do que $20 \mathrm{~m}$ são encontradas em alguns canais entre as ilhas, na foz do Paraguaçu e no Canal de Itaparica-Salvador, onde atingem valores maiores do que $30 \mathrm{~m}$ em média, podendo, localmente, exceder $50 \mathrm{~m}$.

* Programa de Pesquisa e Pós-Graduação em Geofísica e Instituto de Geociências da UFBa, Rua Caetano Moura, 123 Federação - 40000 - Salvador (BA)

** Programa de Pesquisa e Pós-Graduação em Geofisica e Instituto de Geociências da UFBa, Rua Caetano Moura, 123 Federação - 40000 - Salvador (BA) 


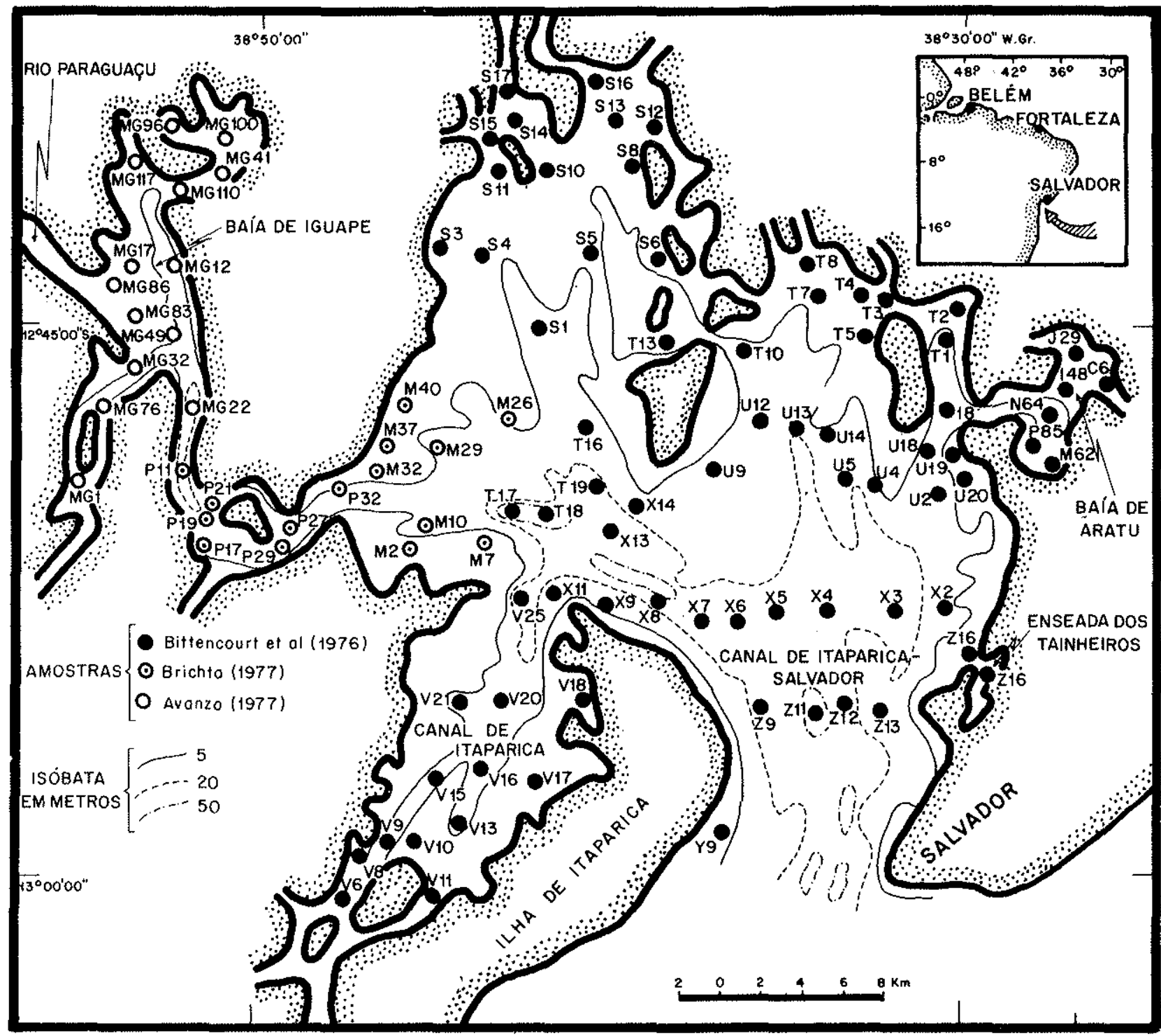

Figura 1 - Mapa fisiográfico e de localização das amostras

A rede hidrográfica que deságua na baía é embrionária, sendo que a linha de divisão. de águas se situa a 1 ou $2 \mathrm{~km}$ de suas margens, com exceção do Rio Paraguaçu, um dos maiores rios do Estado da Bahia, que desemboca na costa do lado oeste da baía. Quanto às condições hidrológicas no interior da baía, são pouco conhecidas, principalmente no que se refere ao padrão de circulação.

O clima da Baía de Todos os Santos, segundo a classificação de Köppen (Andrea, 1962) é do tipo Af, quente e úmido, com pluviosidade média anual de $1.800 \mathrm{~mm}$. As precipitações maiores se verificam de abril a agosto.

Foi utilizado um total de 104 amostras coletadas por Bittencourt et al. (1976), Avanzo (1977) e Brichta (1977), (Fig. 1).

MINERALOGIA E DISTRIBUIÇÃO DOS MI-
NERAIS DE ARGILA A mineralogia da fração argilosa $(<2 \mu)$ foi determinada através da difração de raios $\mathrm{X}$, utilizando-se um difratômetro PhillipsNorelco, radiação $\mathrm{Cu} \mathrm{K}{ }^{\alpha}$. A identificação e análise semiquantitativa dos minerais de argila foram baseadas nos métodos apresentados em Oinuma et al: (1959) e Biscaye (1965).

Os minerais de argila encontrados foram a caolinita, a ilita e a montmorillonita. Além desses minerais aparecem o quartzo e calcita.

Caolinita: Identificada basicamente através da reflexão a $7 \AA$, a caolinita aparece em todas as amostras estudadas, constituindo, na maioria das mesmas, o mineral de argila predominante na Baía de Todos os Santos (Fig. 2). As percentagens mais altas de caolinita aparecem na metade sul, onde atingem valores superiores a $60 \%$ do total de minerais de argila pre- 


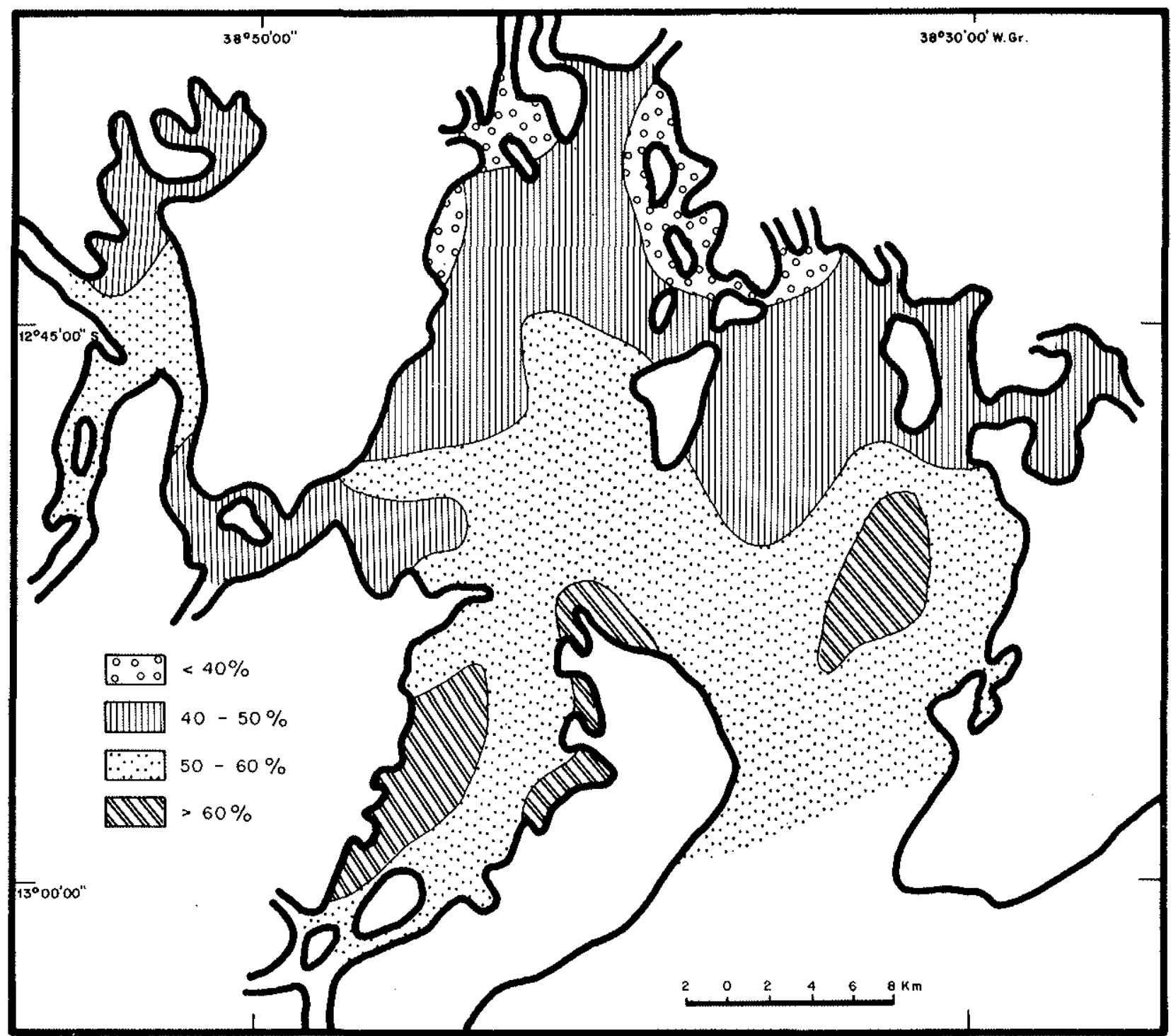

Figura 2 - Mapa de distribuição da caolinita

sentes, e decrescem para norte, onde os valores podem ser inferiores a $40 \%$. Na Baía de Iguape, os valores máximos da percentagem de caolinita, entre 50 e $60 \%$, aparecem na parte central da mesma (região frontal à desembocadura do Rio Paraguaçu), enquanto que no restante dessa baía os valores estão compreendidos entre 40 e $50 \%$.

Montmorillonita: Os picos a $14 \AA$ que aparecem nos diagramas de raios $\mathrm{X}$, e que passam a 16,5-18 $\AA$ após saturação com etileno-glicol, foram considerados como do grupo da montmorillonita. $O$ índice de cristalinidade [razão V/P de Biscaye, (1965)] é, na grande maioria das amostras, inferior a 0,5 , evidenciando um material com estrutura pouco ordenada.

$\mathrm{Na}$ Baía de Todos os Santos (Fig. 3) as percentagens de montmorillonita apresentam valores mais altos, superiores a $30 \%$, na região frontal ao canal que a liga com a Baía de Iguape, diminuindo gradativamente para leste, onde valores inferiores a $10-15 \%$ podem ser encontrados na região próxima à entrada da Baía de Aratu e nas zonas dos canais de Itaparica e Itaparica-Salvador. Na Baía de Iguape, as percentagens de montmorillonita são superiores a $30 \%$, exceto na parte central (região frontal à desembocadura do Rio Paraguaçu), onde estão conpreendidas entre 10 a $15 \%$.

Ilita: Os picos a 10,5 e $3,3 \AA$, não afetados pela glicolação, foram atribuídos ao grupo da ilita.

Na região estudada (Fig. 4) as percentagens mais baixas de ilita, inferiores a $25 \%$, são encontradas na região da Baía de Iguape, na zona centro-oeste da Baía de Todos os Santos (zona frontal ao canal que liga a Baía de Todos os Santos à Baía de Iguape) e na metade oeste do canal de ltaparica. A partir dessas 


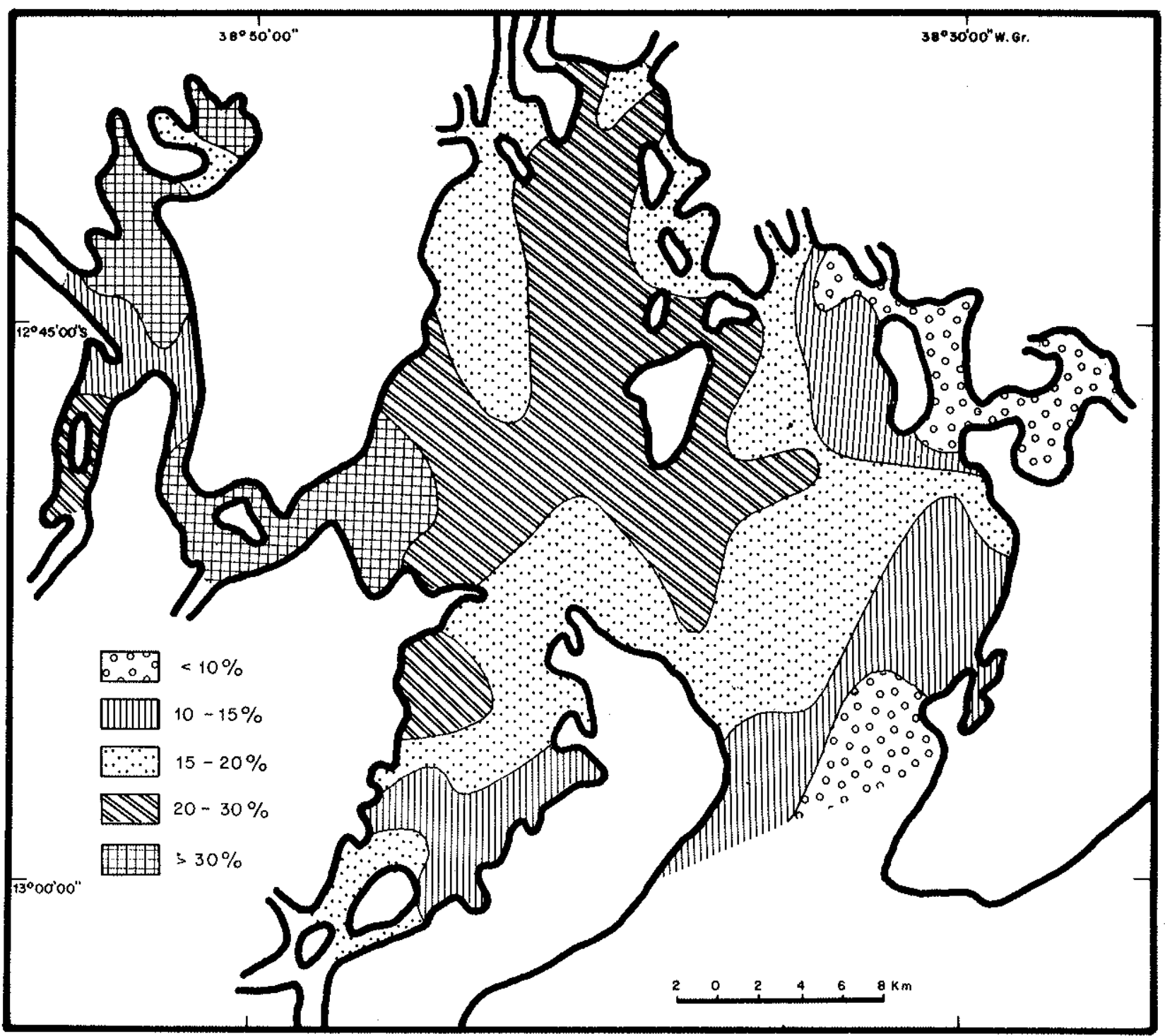

Figura 3 - Mapa de distribuição da montmorillonita

regiões, que constituem a zona de influência do Rio Paraguaçu, as percentagens de ilita aumentam gradativamente para o interior da Baía de Todos os Santos, atingindo valores entre 25 e $30 \%$ na parte centro-oeste, entre 30 e $35 \%$ na região do canal de Itaparica-Salvador, e superiores a $40 \%$ na região norte e nordeste. $\mathrm{Na}$ metade leste do canal de Itapárica os teores de ilita estão geralmente compreendidos entre 25 e $30 \%$.

Quartzo e calcita: Identificados respectivamente pelas reflexões a 3,33 e $3,03 \mathrm{~A}$, esses minerais estão presentes na fração argilosa dos sedimentos da Baía de Todos os Santos em percentagens geralmente inferiores a $10 \%$, conjuntamente.

\section{ASPECTOS GEOQUIMICOS A composição quí-} mica da fração argilosa dos sedimentos do fundo da Baía de Todos os Santos (Tab. I) foi determinada, utilizando-se‘ um espectômetro de absorção atômica Perkin Elmer (403). Os coeficientes de correlação linear entre os diferentes elementos entre si, bem como com as percentagens dos minerais de argila presentes, são mostrados na Tab. II.

Silício e Alumínio: Os teores médios de $\mathrm{S}_{\mathrm{i}} \mathrm{O}_{2}$ e $\mathrm{A}_{2} \mathrm{O}_{3}$ são respectivamente 46,83 e $21,57 \%$, enquanto que a rázão $\mathrm{S}_{\mathrm{j}} \mathrm{O}_{2} / \mathrm{A}_{2} \mathrm{O}_{3}$ (entre as percentagens em peso) tem um valor médio de 2,17. No interior da Baía de Todos os Santos (Fig. 5) valores mais baixos da razão $\mathrm{S}_{i} \mathrm{O}_{2} / \mathrm{A}_{2} \mathrm{O}_{3}$, inferiores a 2,00 , aparecem no Canal de Itaparica-Salvador, na parte norte do Canal de Itaparica e em pequenas zonas isoladas a norte $\mathrm{e}$ nordeste. A partir do Canal de Itaparica-Salvador, a razão $\mathrm{S}_{\mathrm{j}} \mathrm{O}_{2} / \mathrm{A}_{2} \mathrm{O}_{3}$ aumenta para o norte da baía onde pode alcançar valores superiores a 2,40 . No canal de Itaparica, a razão $\mathrm{S}_{\mathrm{i}} \mathrm{O}_{2} / \mathrm{Al}_{2} \mathrm{O}_{3}$ aumenta gradativa- 


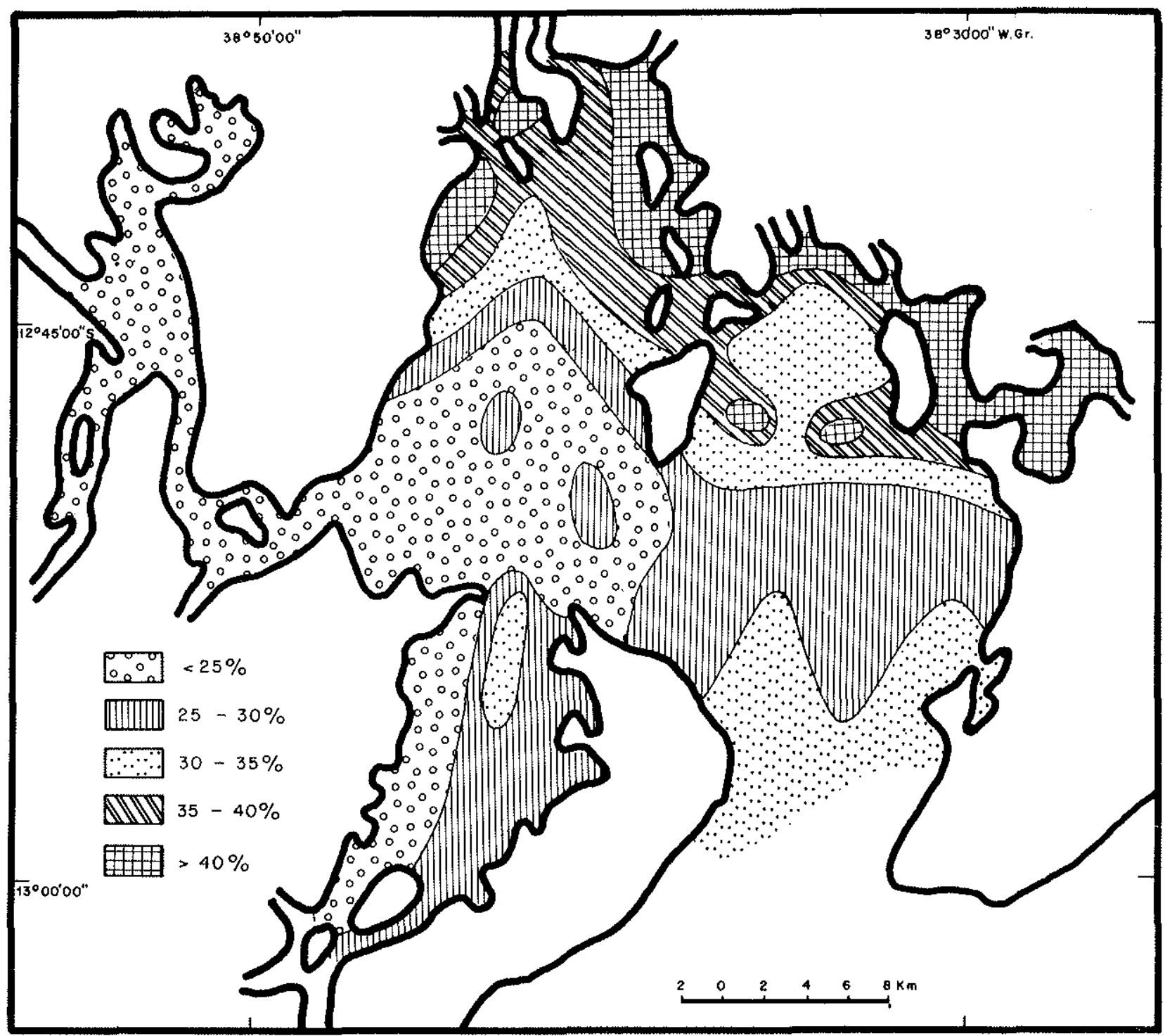

Figura 4-Mapa de distribuição da ilita

mente para o sul onde atinge valores da ordem de 2,40. Na Baía de Iguape os valores mais baixos da razão $\mathrm{S}_{\mathrm{i}} \mathrm{O}_{2} / \mathrm{Al}_{2} \mathrm{O}_{3}$, entre 2,00 e 2,20 , aparecem näs partes central e sul da mesma; ao norte e na zona do canal que a liga com a Baía de Todos os Santos aparecem, respectivamente, valores entre 2,20 e 2,40 , e superiores a 2,40 .

A distribuição da razão $\mathrm{S}_{\mathrm{i}} \mathrm{O}_{2} / \mathrm{A}_{2} \mathrm{O}_{3}$ reflete essencialmente a repartição dos diferentes minerais de argila, sendo geralmente menor nas áreas com maiores percentagens de caolinita (vide Fig. 2) e aumentando nas zonas mais ricas em ilita e montmorillonita (vide Figs. 3 e 4). Esses fatos estão em acordo com as razões $\mathrm{S}_{\mathrm{i}} \mathrm{O}_{2} / \mathrm{A} \ell_{2} \mathrm{O}_{3}$ de aproximadamente $1,18,1,88$ e 3,00 para a caolinita, ilita e montmorillonita, respectivamente, calculadas através de dados obtidos em Weaver e Pollard (1973). Os valores da razão $\mathrm{S}_{4} \mathrm{O}_{2} / \mathrm{A}_{2} \mathrm{O}_{3}$, calculados a partir das proporções dos diferentes mi- nerais argilosos presentes nas amostras estudadas, são geralmente menores do que os valores reais obtidos através das análises químicas, o que provavelmente é devido à presença de sílica livre na fração argilosa.

Potássio e Sódio: $\mathrm{O}$ teor de $\mathrm{K}_{2} \mathrm{O}$ varia entre $1,40 \mathrm{e}$ $3,50 \%$, com valor médio de $2,06 \%$. O teor de potássio está relacionado com a quantidade de ilita presente na amostra (Fig. 6), apresentando uma correlação positiva com a percentagem desse mineral. Através da região (Fig. 7) os valores menores dos teores de $\mathrm{K}_{2} \mathrm{O}$, inferiores a $1,80 \%$, são encontrados na Baía de lguape, na zona centro-oeste da Baía de Todos os Santos (zona frontal ao canal que liga a Baía de Todos os Santos à Baía de Iguape), no Canal de Itaparica-Salvador e nas partes oeste e sul do Canal de Itaparica. Estas últimas zonas constituem as regiões com os menores teores de ilita (vide Fig. 4). A partir dessas 
Tabela l - Composição química da fração argilosa dos sedimentos do fundo da Baía de Todos os Santos

\begin{tabular}{|c|c|c|c|c|c|c|c|c|c|c|c|c|c|c|c|c|}
\hline Amostra & $\mathrm{S}_{i} \mathrm{O}_{2}$ & $\mathrm{~A} \ell_{2} \mathrm{O}_{3}$ & $\mathrm{CaO}$ & $\mathrm{MgO}$ & $\mathrm{Na}_{2} \mathrm{O}$ & $\mathrm{K}_{2} \mathrm{O}$ & $\mathrm{MnO}$ & $\mathrm{Fe}_{2} \mathrm{O}_{3}$ & $\mathrm{~T}_{i} \mathrm{O}_{2}$ & $\begin{array}{l}\text { Perda a } \\
1000^{\circ} \mathrm{C}\end{array}$ & $\frac{\mathrm{SiO}_{2}}{\mathrm{~A}_{\ell_{2} \mathrm{O}_{3}}}$ & $\mathrm{Sr}$ & $\mathrm{Cu}$ & $\mathrm{Zn}$ & $\mathrm{Cr}$ & $\mathrm{Ni}$ \\
\hline 18 & 45,27 & 19,42 & 3,07 & 3,37 & 0,30 & 2,41 & 0,09 & 8,58 & 1,00 & 15,89 & 2,33 & 45 & 50 & 130 & 440 & 30 \\
\hline 6 & 45,28 & 23,10 & 0,34 & 3,11 & 0,66 & 2,51 & 0,05 & 8,00 & 0,88 & 15,68 & 1,96 & 14 & 70 & 190 & 60 & 40 \\
\hline 29 & 47,77 & 24,14 & 0,34 & 2,94 & 0,40 & 2,43 & 0,06 & 8,11 & 1,00 & 12,62 & 1,97 & 18 & 70 & 290 & 70 & 30 \\
\hline 48 & 30,32 & 28,34 & 0,76 & 3,28 & 0.44 & 2,52 & 0,09 & 8,34 & 1,00 & 24,02 & 1,07 & 18 & 60 & 270 & 80 & 30 \\
\hline 2 & 46,66 & 21,00 & 2,12 & 2,94 & 1,16 & 1,74 & 0,04 & 7,95 & 0,77 & 14,97 & 2,22 & 20 & 40 & 110 & 60 & 30 \\
\hline $\mathrm{M}$ & 50,00 & 21,00 & 3,42 & 3,02 & 1,55 & 1,77 & 0,05 & 8,84 & 0,88 & 10,20 & 2,38 & 25 & 40 & 140 & 90 & 30 \\
\hline 10 & 49,72 & 19,42 & 3,47 & 2,71 & 1,02 & 1,97 & 0,04 & 7,82 & 1,00 & 12,81 & 2,56 & 28 & 40 & 100 & 70 & 40 \\
\hline 26 & 40,27 & 18,90 & 1,96 & 2,83 & 0,40 & 1,58 & 0,03 & 7,32 & 0,77 & 25,15 & 2,13 & 20 & 60 & 110 & 80 & 40 \\
\hline 29 & 45,83 & 21,52 & 1,81 & 2,81 & 1,22 & 1,84 & 0,05 & 8,45 & 1,00 & 14,97 & 2,12 & 24 & 60 & 110 & 350 & 30 \\
\hline 32 & 54,44 & 21,52 & 1,54 & 2,81 & 1,18 & 1,76 & 0,04 & 8,56 & 0,88 & 8,09 & 2,52 & 20 & 40 & 110 & 70 & 40 \\
\hline 37 & 58,24 & 18,41 & 1,81 & 2,65 & 0,94 & 2,04 & 0,04 & 6,67 & 1,11 & 9,03 & 3,16 & 23 & 40 & 110 & 130 & 30 \\
\hline 40 & 46,94 & 22,04 & 0,95 & 2,97 & 1,21 & 1,87 & 0,05 & 9,86 & 1,00 & 12,28 & 2,12 & 15 & 40 & 120 & 120 & 40 \\
\hline M 62 & 49,16 & 20,46 & 0,52 & 3,40 & 0,55 & 2,61 & 0,14 & 9,28 & 1,11 & 12,01 & 2,40 & 18 & 60 & 140 & 70 & 50 \\
\hline MGl & 44,44 & 21,00 & 0,37 & 1,90 & 0,37 & 1,74 & 0,01 & 10,15 & 1,11 & 18,92 & 2,11 & 13 & 100 & 160 & 70 & 50 \\
\hline $\mathrm{MGl2}$ & 49,72 & 21,00 & 0,49 & 2,34 & 0.74 & 1.40 & 0,05 & 7,84 & 0,77 & 14,78 & 2,36 & 11 & 40 & 130 & 60 & 30 \\
\hline MG 17 & 44,44 & 23,10 & 0,31 & 1,55 & 0,30 & 1,40 & 0,02 & 8,17 & 1,11 & 19,49 & 1,92 & 11 & 80 & 150 & 60 & 40 \\
\hline $\mathrm{MG} 22$ & 46,66 & 19,42 & 1,29 & 2,36 & 1,26 & 2,14 & 0,14 & 8,26 & 0,88 & 18,88 & 2,40 & 15 & 40 & 110 & 50 & 30 \\
\hline$M G 32$ & 43,61 & 17,32 & 0,71 & 2,28 & 1,55 & 1,66 & 0,03 & 11,22 & 0,77 & 19,66 & 2,51 & 11 & 30 & 160 & 140 & 40 \\
\hline MG 41 & 48,61 & 21,52 & 0,83 & 2,02 & 1,26 & 1,74 & 0,03 & 8,62 & 1,00 & 14,02 & 2,25 & 11 & 40 & 120 & 40 & 30 \\
\hline MG 49 & 43,33 & 18,36 & 1,53 & 2,26 & 1,67 & 1,46 & 0,04 & 7,25 & 0,88 & 22,25 & 2,36 & 16 & 60 & 160 & 60 & 40 \\
\hline MG 76 & 48,05 & 24,67 & 0,77 & 2,00 & 1,11 & 1,53 & 0,03 & 7,25 & 1,00 & 14,02 & 1,94 & 13 & 40 & 140 & 60 & 30 \\
\hline MG 83 & 47,22 & 23,10 & 0,67 & 2,00 & 1,94 & 1,46 & 0,02 & 7,58 & 0,88 & 15,72 & 2,04 & 11 & 40 & 120 & 80 & 40 \\
\hline MG 86 & 50,27 & 23,62 & 0,67 & 2,02 & 1,50 & 1,53 & 0,02 & 7,25 & 0,88 & 11,58 & 2,12 & 11 & 40 & 130 & 40 & 30 \\
\hline MG96 & 50,27 & 21,00 & 0,60 & 2,42 & 1,34 & 2,01 & 0,01 & 7,00 & 1,00 & 15,97 & 2,39 & 9 & 100 & 130 & 50 & 30 \\
\hline MG 100 & 54,44 & 24,14 & 1,01 & 2,34 & 1,11 & 1,74 & 0,02 & 7,15 & 0,88 & 8,09 & 2,25 & 11 & 40 & 220 & 40 & 30 \\
\hline$M G \| 10$ & 53,05 & 24,14 & 0,54 & 2,44 & 0,74 & 1,60 & 0,03 & 8,45 & 1,00 & 9,37 & 2,19 & 10 & 30 & 130 & 70 & 30 \\
\hline$M G \| 7$ & 55,55 & 23,08 & 0,28 & 1,99 & 0,60 & 1,53 & 0,02 & 7,00 & 1,00 & 9,82 & 2,40 & 10 & 50 & 110 & 90 & 30 \\
\hline$N \quad 64$ & 43,33 & 21,00 & 2,00 & 3,50 & 0,44 & 2,48 & 0,09 & 8,78 & 1,00 & 18,02 & 2,06 & 28 & 60 & 380 & 60 & 40 \\
\hline 11 & 52,22 & 21,00 & 0,97 & 2,58 & 0,71 & 1,66 & 0,06 & 8,97 & 1,00 & 11,96 & 2,48 & 19 & 50 & 110 & 90 & 30 \\
\hline 17 & 45,00 & 19,42 & 0,61 & 2,54 & 0,72 & 1,59 & 0,06 & 11,69 & 0,77 & 17,69 & 2,31 & 15 & 50 & 110 & 20 & 40 \\
\hline 19 & 47,50 & 22,04 & 0,95 & 2,62 & 0,61 & 1,65 & 0,06 & 8,91 & 1,00 & 14,84 & 2,15 & 20 & 60 & 110 & 60 & 30 \\
\hline 21 & 47,22 & 21,00 & 1,07 & 2,60 & 0,80 & 1,53 & 0,03 & 8,08 & 1,00 & 15,62 & 2,24 & 18 & 50 & 110 & 20 & 40 \\
\hline 27 & 52,22 & 21,52 & 2,11 & 2,66 & 0,75 & 1,81 & 0,06 & 9,43 & 1,00 & 9,9 & 2,42 & 21 & 60 & 120 & 100 & 50 \\
\hline 29 & 49,16 & 21,52 & 1,12 & 2,73 & 1,07 & 1,69 & 0,10 & 8,22 & 1,00 & 13,02 & 2,28 & 20 & 50 & 110 & 80 & 30 \\
\hline 32 & 49,72 & 22,04 & 0,93 & 3,05 & 1,02 & 1,66 & 0,05 & 8,36 & 0,88 & 12,87 & 2,25 & 19 & 50 & 110 & 70 & 30 \\
\hline 85 & 45,83 & 21,00 & 0,85 & 5,54 & 1,62 & 3,50 & $0,0^{7} 7$ & 13,76 & 1,22 & 8,08 & 2,18 & 18 & 60 & 100 & 30 & 50 \\
\hline 1 & 49,16 & 21,00 & 0,98 & 3,72 & 0,83 & 2,43 & 0,05 & 8,34 & 0,8 & 12,18 & 2,34 & 19 & 50 & 120 & 50 & 40 \\
\hline 3 & 49,16 & 21,51 & 0,41 & 3,16 & 1,37 & 2,05 & 0,03 & 7,14 & 0,8 & 15,22 & 2,28 & 14 & 80 & 130 & 30 & 30 \\
\hline 4 & 51,94 & 21,00 & 0,75 & 3,44 & 1,26 & 2,18 & 0,05 & 8,01 & 0,88 & 11,35 & 2,47 & 16 & 40 & 110 & 30 & 30 \\
\hline 5 & 53,82 & 21,43 & 1,51 & 3,75 & 1,61 & 2,34 & 0,06 & 9,21 & 1,00 & 7,09 & 2,51 & 24 & 40 & 120 & 130 & 40 \\
\hline 6 & 52,50 & 20,46 & 1,62 & 3,73 & 0,84 & 2,52 & 0,05 & & & & & 16 & 60 & 130 & 40 & 40 \\
\hline 8 & 55,27 & 20,46 & 0,54 & 3,73 & 1,78 & 2,70 & 0,05 & 2,71 & 0,88 & 11,49 & 2,70 & 13 & 60 & 130 & 20 & 40 \\
\hline 10 & 53,82 & 21,43 & 0,50 & 4,00 & 0,97 & 2,63 & 0,04 & 9,1 & 1,0 & 6,5 & 2,51 & 10 & 60 & 130 & 40 & 30 \\
\hline 11 & 56,11 & 20,21 & 0,56 & 3,73 & 0,74 & 2,53 & 0,04 & 8,53 & 1,00 & 6,25 & 2,77 & 10 & 90 & 140 & 120 & 40 \\
\hline 12 & 51,94 & 13,64 & 0,33 & 3.91 & 1,11 & 2,87 & 0,05 & 8,10 & 0,88 & 17,41 & 3,80 & 8 & 60 & 210 & 150 & 40 \\
\hline 13 & 51,11 & 21,00 & 0,55 & 3,88 & & 2,76 & 0,04 & & 1,00 & 10,85 & & 10 & 60 & & 40 & 50 \\
\hline 14 & 51,11 & 22,04 & 0,3 & 3,9 & & 2,7 & 0,0 & 7,8 & 1,0 & 9, & 2,31 & 10 & 60 & 15 & 20 & 30 \\
\hline 15 & 43,88 & 18,90 & 0,37 & 3,14 & 1, & 2,32 & 0,03 & 7,3 & 0,8 & 21,40 & 2,32 & 9 & 190 & 150 & 40 & 30 \\
\hline 16 & 51,11 & 21,52 & 0,85 & 4,12 & 1,07 & 2,91 & 0,05 & 8,22 & 1,11 & 8,81 & 2,37 & 15 & 90 & 180 & 60 & 30 \\
\hline 17 & 49,44 & 21,00 & 0,30 & 3,03 & 1,13 & 2,74 & 0,02 & 7,31 & 1,11 & 14,12 & 2,35 & 5 & 80 & 180 & 30 & 30 \\
\hline 1 & 44,44 & 22,04 & 1,04 & 3,48 & 2,00 & 2,80 & 0,06 & 8,03 & 1,00 & 14,87 & & 20 & 50 & 120 & 60 & 40 \\
\hline 2 & 51,38 & 23,06 & 0,52 & 3,5 & 0,8 & 2,90 & 0,0 & & 1,11 & 7,47 & 2,22 & 25 & 60 & 140 & 50 & 40 \\
\hline 3 & 49,72 & 21,52 & 0,40 & 3,03 & 1,06 & 2,74 & 0,0 & 7,3 & 1,11 & 12,54 & 2,31 & 14 & 60 & 130 & 150 & 30 \\
\hline 4 & 49,44 & 21,00 & 1,76 & 3,64 & 0,86 & 2,71 & 1,07 & 8,48 & 1,11 & 9,73 & 2,35 & 25 & 60 & 130 & 240 & 40 \\
\hline 5 & 45,00 & 18,90 & 6,27 & 3,54 & 1,47 & 2,41 & 0,06 & 7,33 & 0,77 & 14,59 & 2,38 & 81 & 40 & 110 & 80 & 30 \\
\hline 7 & 42,77 & 22,16 & 3,70 & 3,63 & 0,95 & 2,40 & 0,06 & 7,78 & 0,88 & & & 31 & 40 & 110 & 50 & 40 \\
\hline 8 & 37,99 & 24,55 & 1,44 & 3,11 & 0,96 & 2,70 & 0,05 & 6,96 & & & & 29 & 70 & 130 & 80 & 40 \\
\hline 10 & 36,66 & 21,00 & $3 ; 02$ & 3,71 & 1,0 & 2,44 & 1,00 & 7,84 & 0,8 & 21,95 & 1,74 & 34 & 50 & 130 & 100 & 40 \\
\hline 13 & 38,61 & 19,94 & 4,18 & 3,52 & 0,66 & 2,46 & 0,06 & 7,75 & 0,88 & 22,12 & 1,93 & 41 & 50 & 130 & 60 & 40 \\
\hline 16 & 41,38 & 18,36 & 4,46 & 3,42 & 0,74 & 2,03 & 0,08 & 7,58 & 0,88 & 21,54 & 2,25 & 40 & 90 & 120 & 50 & 30 \\
\hline 17 & 45,00 & 21,00 & 0,78 & 3,03 & 1,50 & 1,90 & 0,06 & 7,77 & 0,88 & 18,45 & 2,14 & 31 & 40 & 120 & 70 & 30 \\
\hline 18 & 45,27 & 21,00 & 3,49 & 2,99 & 0,81 & 1,73 & 0,04 & 7,92 & 0,8 & & 2,15 & 29 & 40 & 110 & 50 & 30 \\
\hline 19 & 50,00 & 21,00 & 3,04 & 3,06 & 2,46 & 2,07 & 0,05 & 8,11 & 0,88 & 10,42 & 2,38 & 25 & 40 & 110 & 110 & 40 \\
\hline 2 & 46,11 & 23,10 & 5,97 & 3,82 & 1,31 & 2,47 & 0,11 & 7,75 & 0,88 & 7,45 & 1,99 & 48 & 40 & 120 & 110 & 40 \\
\hline 4 & 43,88 & 21,52 & 6,94 & 3,54 & 1,64 & 2,21 & 0,07 & 7,26 & 088 & 1150 & 203 & 43 & 30 & 110 & 100 & 30 \\
\hline
\end{tabular}


Tabela I - Composição química da fração argilosa dos sedimentos do fundo da Baía de Todos os Santos

Tabela I - (continuação)

\begin{tabular}{|c|c|c|c|c|c|c|c|c|c|c|c|c|c|c|c|c|c|}
\hline $\mathrm{U}$ & 5 & 48,05 & 22,56 & 5,70 & 3,74 & 1,34 & 2,21 & 0,10 & 7,16 & 0,88 & 7,57 & 2,12 & 35 & 40 & 110 & 80 & 40 \\
\hline $\mathrm{U}$ & 9 & 48,88 & 20,46 & 3,84 & 3,44 & 1,27 & 2,01 & 0,07 & 8,10 & 0,88 & 11,24 & 2,38 & 20 & 40 & 130 & 90 & 40 \\
\hline $\mathrm{U}$ & 12 & 52,22 & 19,42 & 3,57 & 3,65 & 1,11 & 2,41 & 0,06 & 8,20 & 0,88 & 8,80 & 2,68 & 35 & 30 & 120 & 70 & 30 \\
\hline $\mathrm{U}$ & 13 & 48,88 & 18,90 & 3,62 & 3,38 & 1,26 & 2,01 & 0,05 & 7,55 & 0,88 & 13,04 & 2,58 & 31 & 40 & 120 & 60 & 40 \\
\hline $\mathrm{U}$ & 14 & 47,22 & 19,94 & 6,12 & 3,42 & 1,17 & 2,07 & 0,05 & 7,14 & 0,88 & 12,72 & 2,36 & 53 & 40 & 110 & 70 & 40 \\
\hline $\mathrm{U}$ & 18 & 51,38 & 23,62 & 3,51 & 3,57 & 1,33 & 2,27 & 0,10 & 8,42 & 0,88 & 4,73 & 2,17 & 35 & 40 & 120 & 90 & 30 \\
\hline $\mathrm{U}$ & 19 & 49,16 & 24,67 & 1,67 & 2,92 & 0,57 & 2,67 & 0,03 & 8,75 & 1,11 & 8,84 & 1,99 & 13 & 90 & 130 & 90 & 40 \\
\hline $\mathrm{U}$ & 20 & 44,74 & 22,68 & 6,05 & 2,92 & 0,62 & 2,47 & 0,07 & 8,95 & 1,00 & 9,37 & 1,97 & 54 & 40 & 130 & 90 & 40 \\
\hline V & 6 & 51,38 & 23,62 & 2,18 & 2,99 & 0,60 & 1,53 & 0,03 & 6,79 & 0,88 & 10,66 & 2,17 & 25 & 50 & 140 & 50 & 30 \\
\hline V & 8 & 54,72 & 23,62 & 0,71 & 2,55 & 1,20 & 1,88 & 0,03 & 7,42 & 1,00 & 6,67 & 2,31 & 14 & 30 & 110 & 70 & 30 \\
\hline V & 9 & 51,38 & 25,20 & 2,20 & 3,11 & 0,91 & 1,88 & 0,05 & 7,44 & 1,00 & 8,17 & 2,03 & 23 & 20 & 120 & 90 & 30 \\
\hline V & 10 & 55,55 & 25,20 & 0,96 & 2,95 & 0,74 & 1,87 & 0,04 & 7,16 & 0,88 & 4,52 & 2,20 & 16 & 20 & 100 & 60 & 30 \\
\hline v & 11 & 51,38 & 22,04 & 3,75 & 3,00 & 0,53 & 1,81 & 0,04 & 6,53 & 0,88 & 10,92 & 2,33 & 33 & 60 & 100 & 60 & 30 \\
\hline V & 13 & 54,16 & 23,08 & 3,21 & 3,13 & 1,22 & 2,01 & 0,04 & 7,55 & 0,88 & 4,86 & 2,34 & 34 & 30 & 110 & 60 & 30 \\
\hline V & 15 & 50,58 & 23,11 & 4,16 & 3,14 & 1,20 & 1,87 & 0,04 & 6,81 & 0,88 & 7,39 & 2,18 & 26 & 30 & 100 & 80 & 40 \\
\hline V & 16 & 43,33 & 22,56 & 0,44 & 3,23 & 1,35 & 2,07 & 0,05 & 6,70 & 0,88 & 18,85 & 1,92 & 36 & 30 & 100 & 70 & 40 \\
\hline V & 17 & 39,44 & 21,00 & 6,43 & 2,93 & 1,33 & 3,86 & 0,03 & 6,53 & 0,77 & 17,99 & 1,87 & 58 & 50 & 120 & 70 & 30 \\
\hline V & 18 & 45,27 & 23,62 & 1,11 & 3,05 & 0,48 & 2,27 & 0,03 & 6,53 & 0,88 & 16,16 & 1,91 & 14 & 60 & 130 & 70 & 30 \\
\hline V & 20 & 41,66 & 27,62 & 4,00 & 3,22 & 1,41 & 2,01 & 0,06 & 6,88 & 0,77 & 13,46 & 1,50 & 34 & 30 & 110 & 70 & 30 \\
\hline V & 21 & 47,77 & 24,14 & 3,21 & 3,25 & 0,64 & 1,94 & 0,04 & 7,46 & 0,88 & 10,78 & 1,97 & 33 & 30 & 110 & 80 & 30 \\
\hline V & 25 & 46,94 & 32,54 & 3,87 & 3,31 & 0,31 & 1,81 & 0,04 & 6,86 & 0,77 & 3,71 & 1,44 & 34 & 30 & 100 & 70 & 40 \\
\hline $\mathrm{X}$ & 2 & 41,38 & 19,42 & 2,79 & 3,28 & 0,66 & 1,74 & 0,05 & 7,36 & 0,77 & 23,46 & 2,13 & 60 & 60 & 130 & 60 & 30 \\
\hline $\mathrm{X}$ & 3 & 40,83 & 23,10 & 6,46 & 3,51 & 0,66 & 1,81 & 0,08 & 8,52 & 0,77 & 13,45 & 1,76 & 45 & 50 & 120 & 80 & 30 \\
\hline$x$ & 4 & 41,38 & 19,94 & 6,44 & 3,32 & 0,74 & 1,87 & 0,06 & 7,74 & 0,77 & 17,61 & 2,07 & 46 & 50 & 130 & 60 & 46 \\
\hline $\mathrm{X}$ & 5 & 43,88 & 19,94 & 5,66 & 3,32 & 0,52 & 1,74 & 0,06 & 9,12 & 0,77 & 14,27 & 2,20 & 24 & 30 & 130 & 80 & 40 \\
\hline $\mathrm{X}$ & 6 & 38,33 & 18,90 & 5,26 & 3,02 & 1,34 & 1,66 & 0,08 & 7,60 & 0,77 & 22,74 & 2,02 & 41 & 30 & 100 & 14 & 30 \\
\hline $\mathrm{X}$ & 7 & 40,55 & 18,90 & 4,94 & 3,14 & 1,11 & 1,74 & 0,05 & 7,61 & 0,77 & 20,79 & 2,14 & 38 & 60 & 140 & 60 & 30 \\
\hline $\mathrm{X}$ & 8 & 43,33 & 20,46 & 6,44 & 3,11 & 0,82 & 1,74 & 0,07 & 7,90 & 0,77 & 14,74 & 2,11 & 51 & 30 & 110 & 70 & 40 \\
\hline $\mathrm{X}$ & 9 & 43,88 & 19,94 & 5,26 & 3,22 & 0,60 & 1,74 & 0,06 & 7,90 & 0,77 & 16,38 & 2,20 & 46 & 40 & 110 & 70 & 40 \\
\hline $\mathrm{X}$ & 11 & 43,33 & 21,00 & 5,27 & 3,57 & 0,82 & 1,81 & 0,04 & 7,48 & 0,77 & 16,24 & 2,06 & 46 & 30 & 120 & 70 & 30 \\
\hline$x$ & 13 & 43,88 & 21,00 & 3,55 & 2,93 & 0,82 & 1,66 & 0,06 & 8,05 & 0,88 & 18,01 & 2,08 & 37 & 30 & 110 & 60 & 40 \\
\hline $\mathrm{X}$ & 14 & 46,66 & 21,00 & 3,28 & 3,51 & 1,79 & 2,07 & 0,06 & 8,31 & 0,66 & 13,45 & 2,22 & 33 & 40 & 130 & 70 & 40 \\
\hline Y & 9 & 36,94 & 16,26 & 13,43 & 3,15 & 0,77 & 1,60 & 0,05 & 5,71 & 0,66 & 21,44 & 2,27 & 89 & 130 & 120 & 70 & 30 \\
\hline Z & 9 & 38,33 & 21,52 & 3,28 & 3,28 & 0,95 & 1,74 & 0,05 & 7,47 & 0,88 & 21,64 & 1,78 & 39 & 50 & 120 & 110 & 30 \\
\hline $\mathrm{Z}$ & 11 & 42,77 & 20,46 & 8,12 & 3,15 & 1,26 & 1,81 & 0,03 & 5,71 & 0,88 & 15,25 & 2,09 & 58 & 50 & 160 & 90 & 30 \\
\hline Z & 12 & 47,22 & 24,14 & 6,47 & 3,48 & 0,97 & 1,81 & 0,06 & 7,94 & 0,88 & 8,13 & 1,95 & 54 & 50 & 130 & 100 & 40 \\
\hline Z & 13 & 35,00 & 23,10 & 6,42 & 3,85 & 1,00 & 1,81 & 0,04 & 7,44 & 0,77 & 20,71 & 1,51 & 54 & 60 & 190 & 80 & 40 \\
\hline Z & 15 & 32,38 & 24,81 & 3,50 & 3,42 & 1,92 & 2,34 & 0,03 & 7,15 & 0,88 & 23,34 & 1,30 & 41 & 70 & 840 & 90 & 30 \\
\hline Z & 16 & 43,33 & 23,10 & 2,06 & 3,33 & 0,61 & 2,47 & 0,07 & 8,04 & 0,88 & 16,31 & 1,87 & 59 & 50 & 200 & 80 & 40 \\
\hline \multicolumn{2}{|c|}{$\begin{array}{l}\text { Média } \\
\text { Desvio }\end{array}$} & 46,89 & 21,61 & 2,58 & 3,12 & 1,02 & 2,08 & 0,07 & 7,96 & 0,91 & 13,81 & 2,19 & 27,42 & $52 ; 17$ & 141,13 & 78,06 & 35,19 \\
\hline \multicolumn{2}{|c|}{ Padrão } & 5,29 & 2,39 & 2,32 & 0,57 & 0,41 & 0,46 & 0,13 & 1,21 & 0,11 & 5,05 & 0,34 & 16,14 & 22,89 & 81,27 & 54,54 & 5,89 \\
\hline
\end{tabular}

Tabela II - Coeficientes de correlação linear entre os diversos elementos e minerais de argila

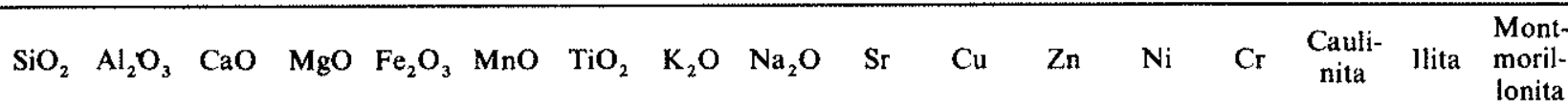

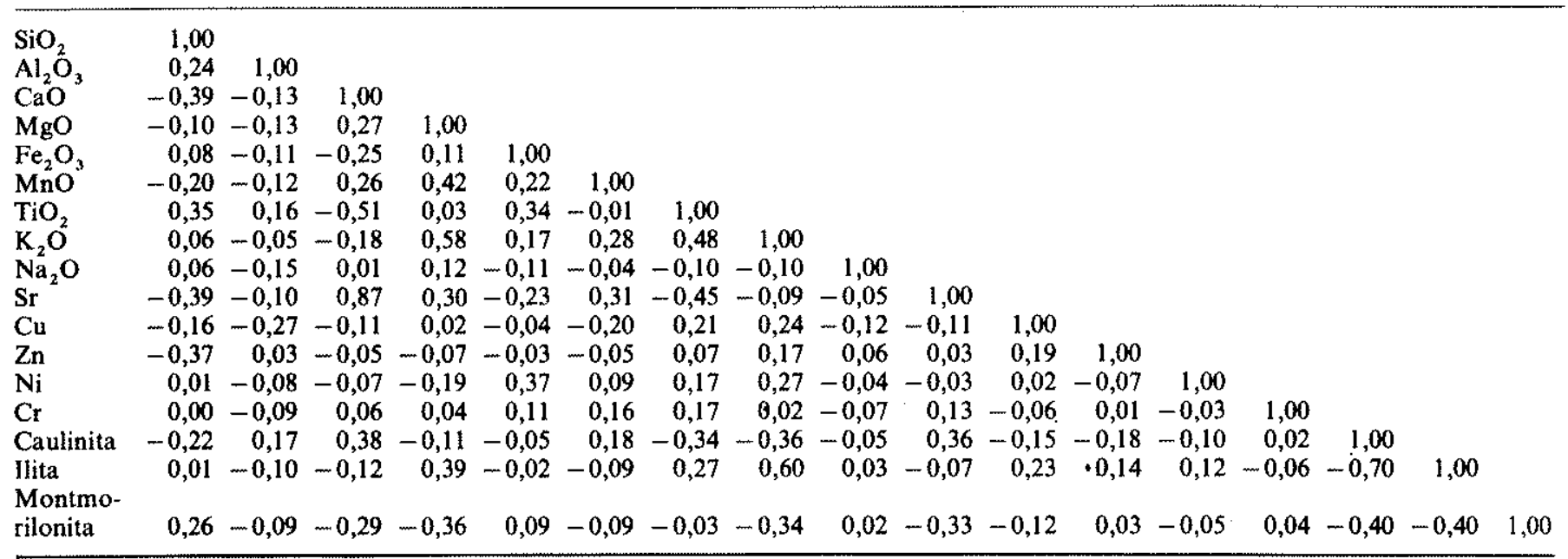




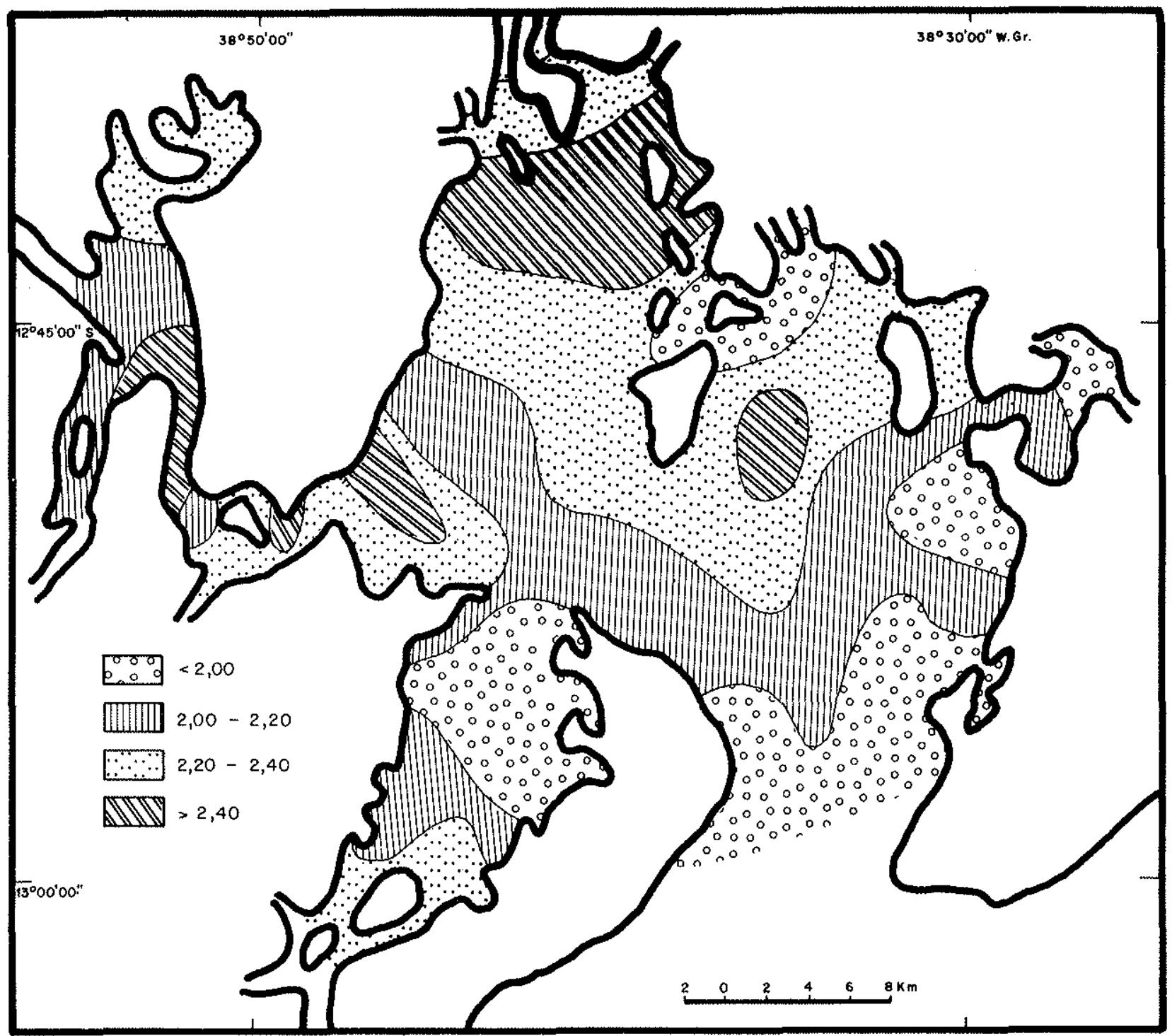

Figura 5-Mapa de distribuição da relação $\mathrm{SiO}_{2} / \mathrm{Al}_{2} \mathrm{O}_{3}$

regiões, o teor de $\mathrm{K}_{2} \mathrm{O}$ aumenta gradativamente para o norte da Baía de Todos os Santos, atingindo valores superiores a $2,60 \%$ no extremo norte, onde as percentagens de ilita são as mais altas.

Os teores de $\mathrm{Na}_{2} \mathrm{O}$ estão compreendidos entre 0,30 e $2,00 \%$, com média de $1,02 \%$. Os indices de correlação extremamente baixos do $\mathrm{Na}_{2} \mathrm{O}$ com as percentagens de caolinita, ilita e montmorillonita, sugerem que o $\mathrm{Na}_{2} \mathrm{O}$ não está ligado particularmente a nenhum desses minerais. Esse fato é também evidenciado pela distribuição aleatória do $\mathrm{Na}_{2} \mathrm{O}$ na região estudada (Fig. 8). Goldschmidt (1958) assinala que parte do sódio associado aos sedimentos argilosos marinhos pode estar presente em pequenos grãos clásticos de albita. $O$ sódio pode ocorrer também adsorvido pelos minerais de argila presentes, sendo que na caolinita a fixação é feita por absorção na superficie, na ilita por mecanismos eletrostáticos de troca de cátions, e na montmorillonita por acomodação em posição interestratificada.

Nos sedimentos da Baía de Todos os Santos não foi observada a presença de albita na fração argilosa, ocorrendo o sódio provavelmente adsorvido pelos minerais de argila.

Cálcio: Os teores de $\mathrm{CaO}$ estão compreendidos entre 0,28 e $13,43 \%$, com valor médio de $2,58 \%$.

Os índices de correlação do $\mathrm{CaO}$ com as percentagens de ilita e montmorillonita são muito baixos e negativos, enquanto que a correlação com a percentagem de caolinita, embora positiva, não é suficientemente significativa. Esses dados indicam que, pelo menos a maior parte do cálcio presente na fração argilosa dos sedimentos do fundo da Baía de Todos os Santos, não está ligada estruturalmente aos minerais de argila. 


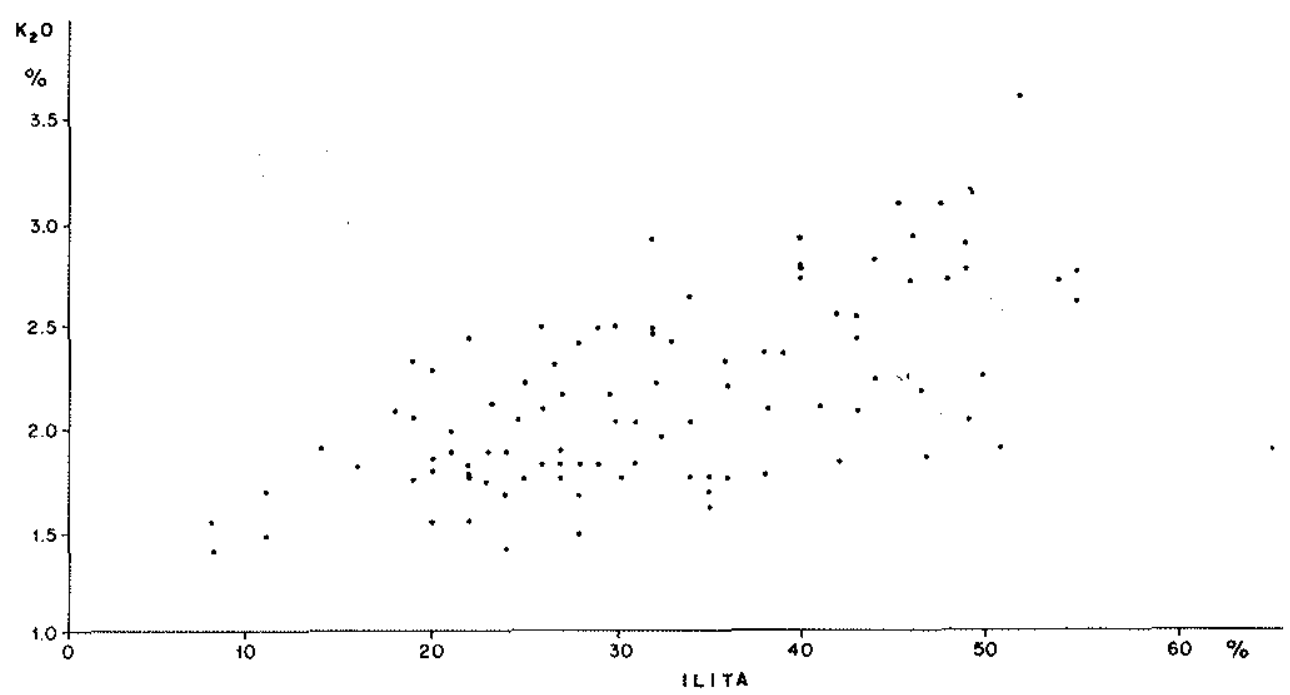

Figura $6-$ Relação entre $\mathrm{K}_{2} \mathrm{O}$ e a percentagem de ilita

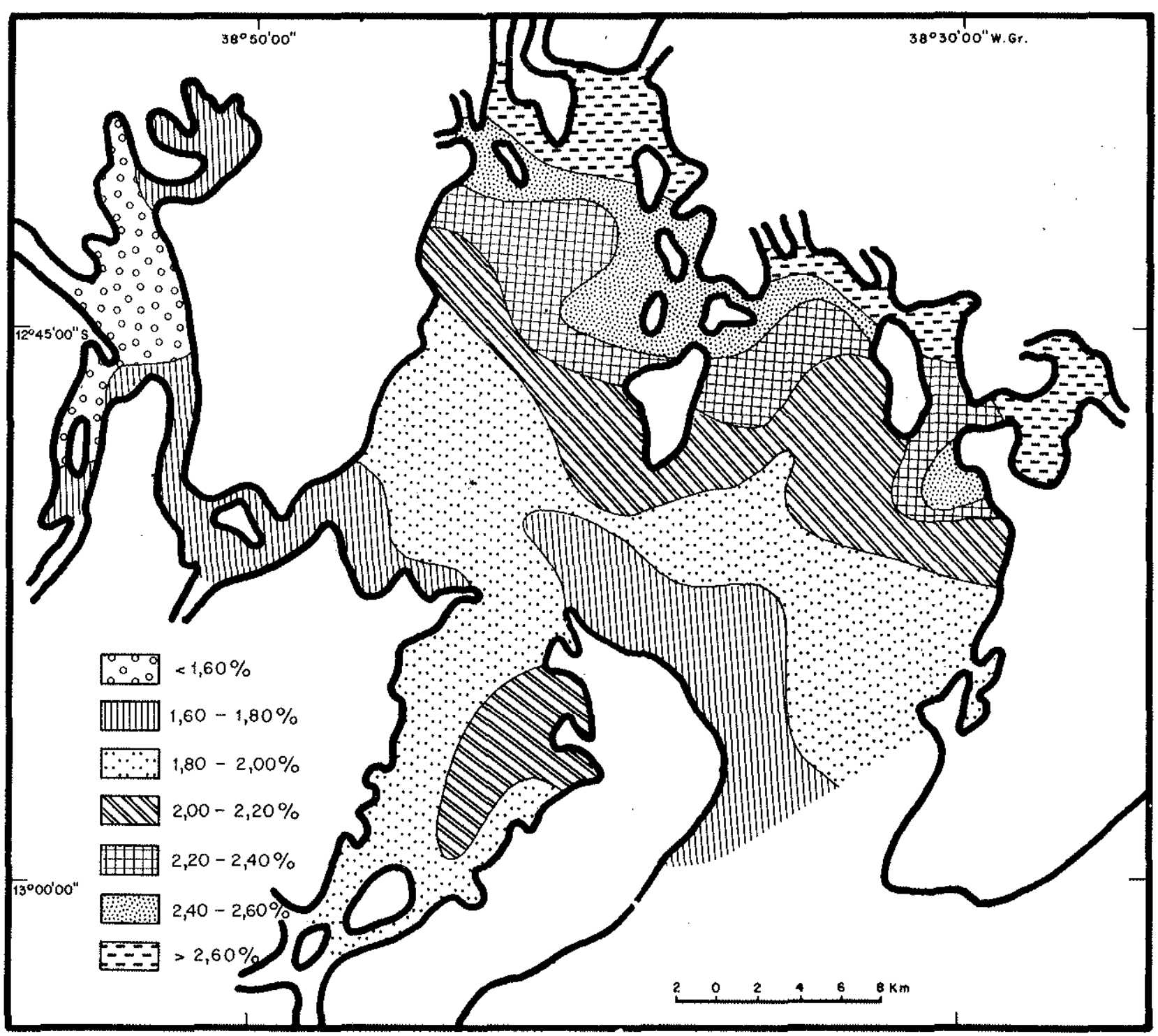

Figura 7 - Mapa de distribuição de $\mathrm{K}_{2} \mathrm{O}$ 


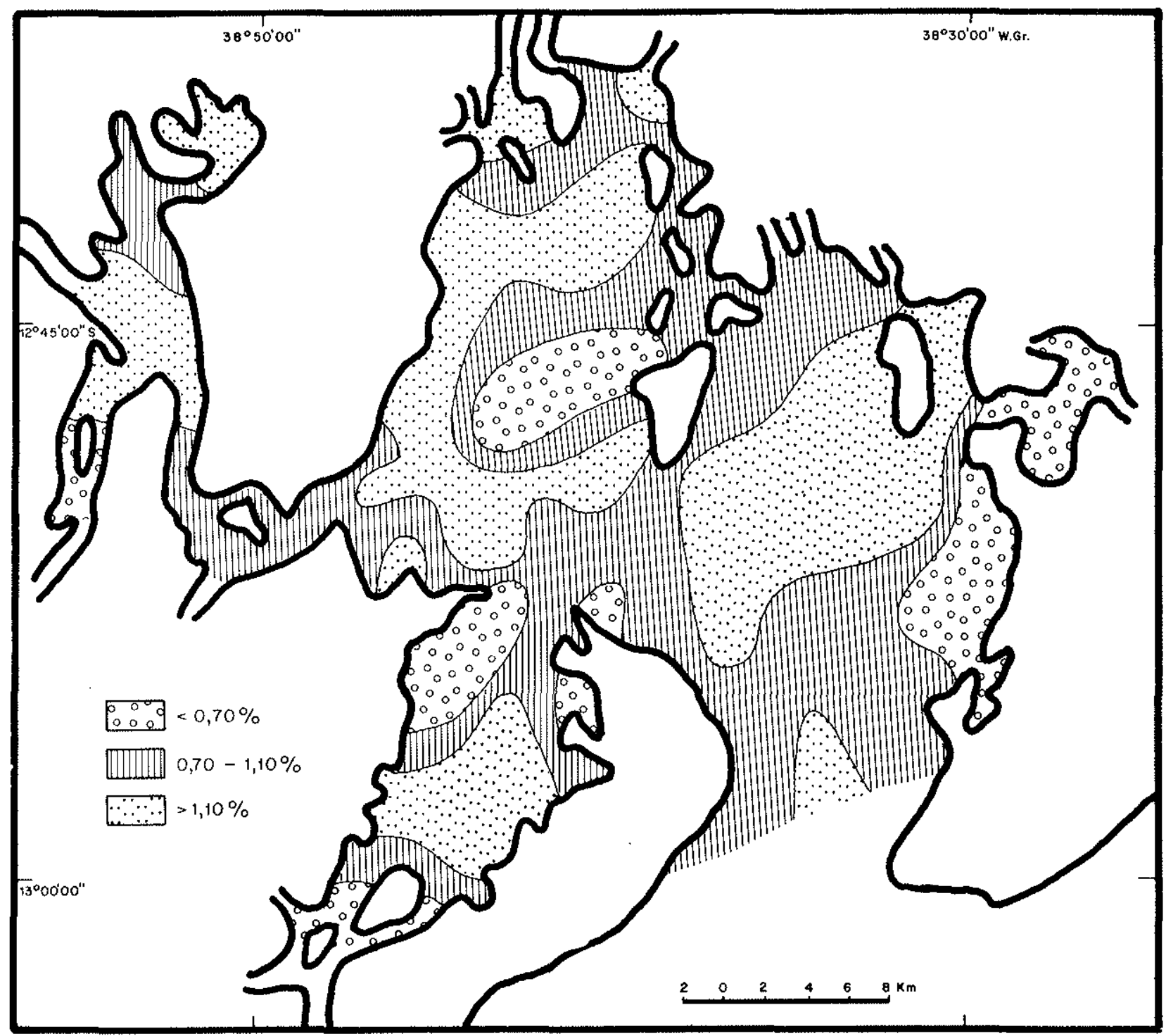

Figura 8 - Mapa de distribuição do $\mathrm{Na}_{2} \mathrm{O}$

Bittencourt et al. (1976) mostram que o teor de $\mathrm{CaCO}_{3}$ nos sedimentos do fundo da Baía de Todos os Santos está relacionado com o material biodetrítico presente e que os seus valores são mais elevados a sudeste do que na parte noroeste da baía. Na fraçâo argilosa as maiores percentagens de $\mathrm{CaO}$ (Fig. 9), superiores a 5,5\%, aparecem a sudeste da área onde a proporção de material biodetrítico é maior, e diminuem gradativamente para noroeste onde o $\mathrm{CaO}$ atinge valores inferiores a $1,5 \%$, nas zonas de menor concentração de biodetritos. Esses dados sugerem que, a maioria do cálcio presente nos sedimentos argilosos do fundo da Baia de Todos os Santos, ocorre sob forma de material biodetrítico fino $(<2 \mu)$ constituido de calcita.

Magnésio: $\mathrm{O}$ teor de $\mathrm{MgO}$ varia entre 1,55 e $5,54 \%$, com valor médio de $3,12 \%$.
O magnésio presente em sedimentos argilosos, ocorre em geral associado estruturalmente a minerais do tipo montmorillonita e clorita (Degens, 1965). $\mathrm{Na}$ região estudada, os teores de $\mathrm{MgO}$ (Fig. 10) tem os seus valores, inferiores a $2,20 \%$, no interior da Baía de Iguape, aumentando gradativamente para o interior da Baía de Todos os Santos, onde a percentagem de $\mathrm{MgO}$ atinge valores superiores a $3,40 \%$ na parte leste dessa baía. A distribuição do $\mathrm{MgO}$ tem, dessa forma, um comportamento inverso ao da percentagem de montmorillonita (Fig. 3), cujos valores mais elevados são encontrados na Baía de Iguape e, os menores, na parte leste da Baía de Todos os Santos. Esse fato sugere que pelo menos a maior parte do $\mathrm{Mg}$ presente na fração inferior a $2 \mu$ independe da percentagem de montmorillonita, dando uma correlação negativa, embora pouco significativa entre ambos. 


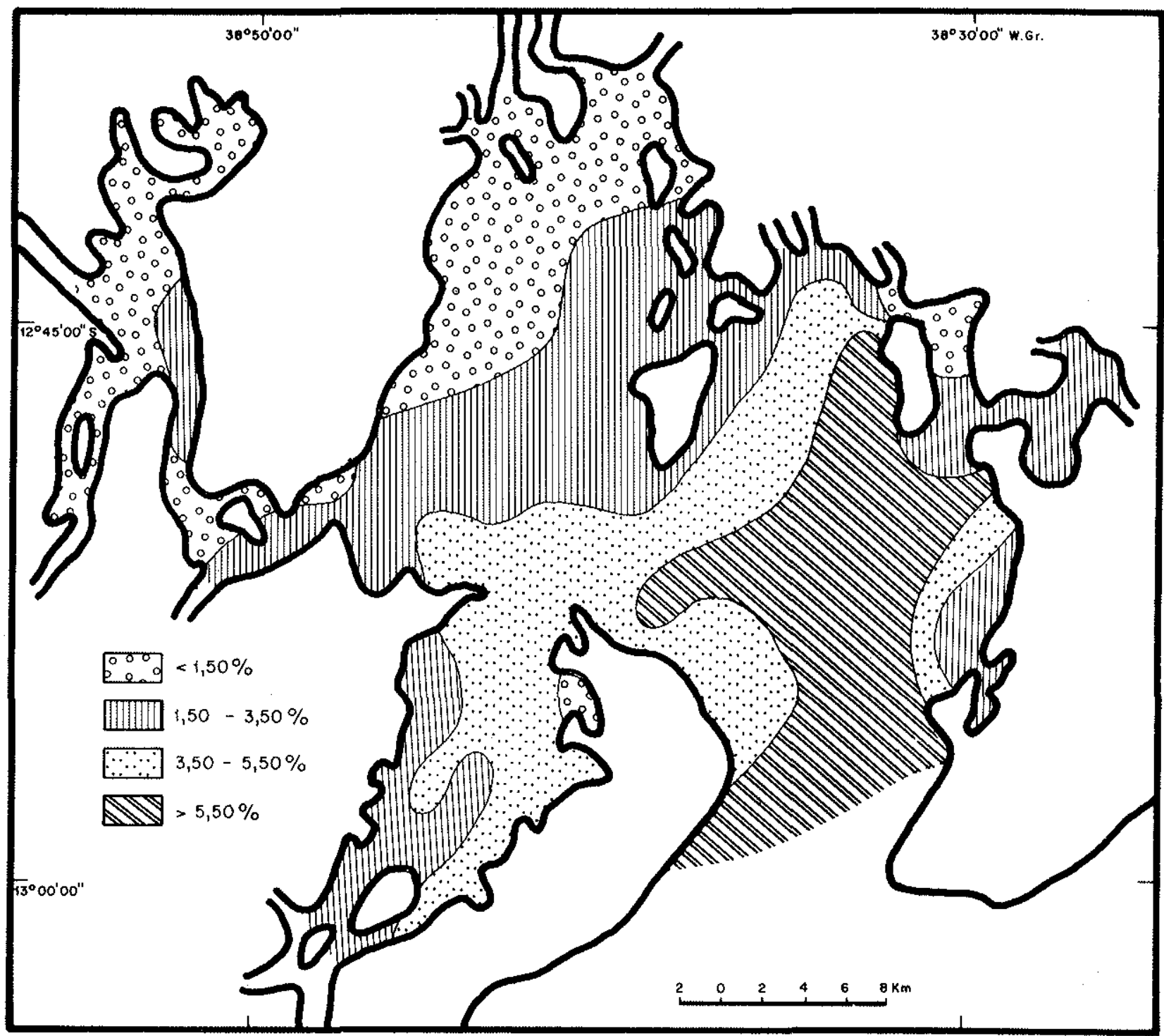

Figura 9 - Mapa de distribuição do $\mathrm{CaO}$

As relações entre $\mathrm{MgO}$ e $\mathrm{K}_{2} \mathrm{O}$ (Fig. 11), e a correlação positiva entre esses óxidos, indicam que a maior parte do magnésio está ligado estruturalmente a ilita.

Ferro: $\mathrm{O}$ teor de $\mathrm{Fe}_{2} \mathrm{O}_{3}$ varia de 5,71 a $13,76 \%$ com um valor médio de $7,96 \%$. Esses valores são elevados em relação ao teor médio de $4,7 \%$ para as rochas argilosas em geral (Degens, 1965; Krauskopf, 1967). Carroll (1958) assinala que o ferro associado aos minerais de argila pode ocorrer dentro da estrutura dos mesmos, como no caso da montmorillonita, ou como óxidos aderidos à superfície das partículas argilosas, principalmente caolinitas de regiões tropicais. Uma pequena percentagem de ferro podè estar presente na estrutura da caolinita em posição octaedral (Robertson et al., 1954; Malden e Meads, 1967).
$\mathrm{Na}$ fração argilosa dos sedimentos do fundo da Baía de Todos os Santos, a ausência da correlação de $\mathrm{Fe}_{2} \mathrm{O}_{3}$ com as percentagens de caolinita, ilita, montmorillonita e com o $\mathrm{K}_{2} \mathrm{O}$, indica que pelo menos a maior parte do ferro não está estruturalmente ligado aos minerais argila, ocorrendo provavelmente disseminado. Bittencourt et al. (1976), Avanzo (1977), Bittencourt e Vilas Boas (1977) e Macedo (1977) mencionam a presença de chamosita, goetita, limonita, e grãos de quartzo com envoltório de óxido de ferro na fração grosseira $(>0,062 \mathrm{~mm}$ ) dos sedimentos da Baía de Todos os Santos, o que favorece a hipótese da ocorrência de compostos de ferro na fração mais fina. Os diagramas de raios $X$ da fração argilosa não evidenciaram a presença de óxidos ou hidróxidos cristalizados de ferro, sugerindo que o mesmo ocorra sob a forma de componentes pobremente cristalizados ou amorfos. Evidentemente, é possível que uma pe- 


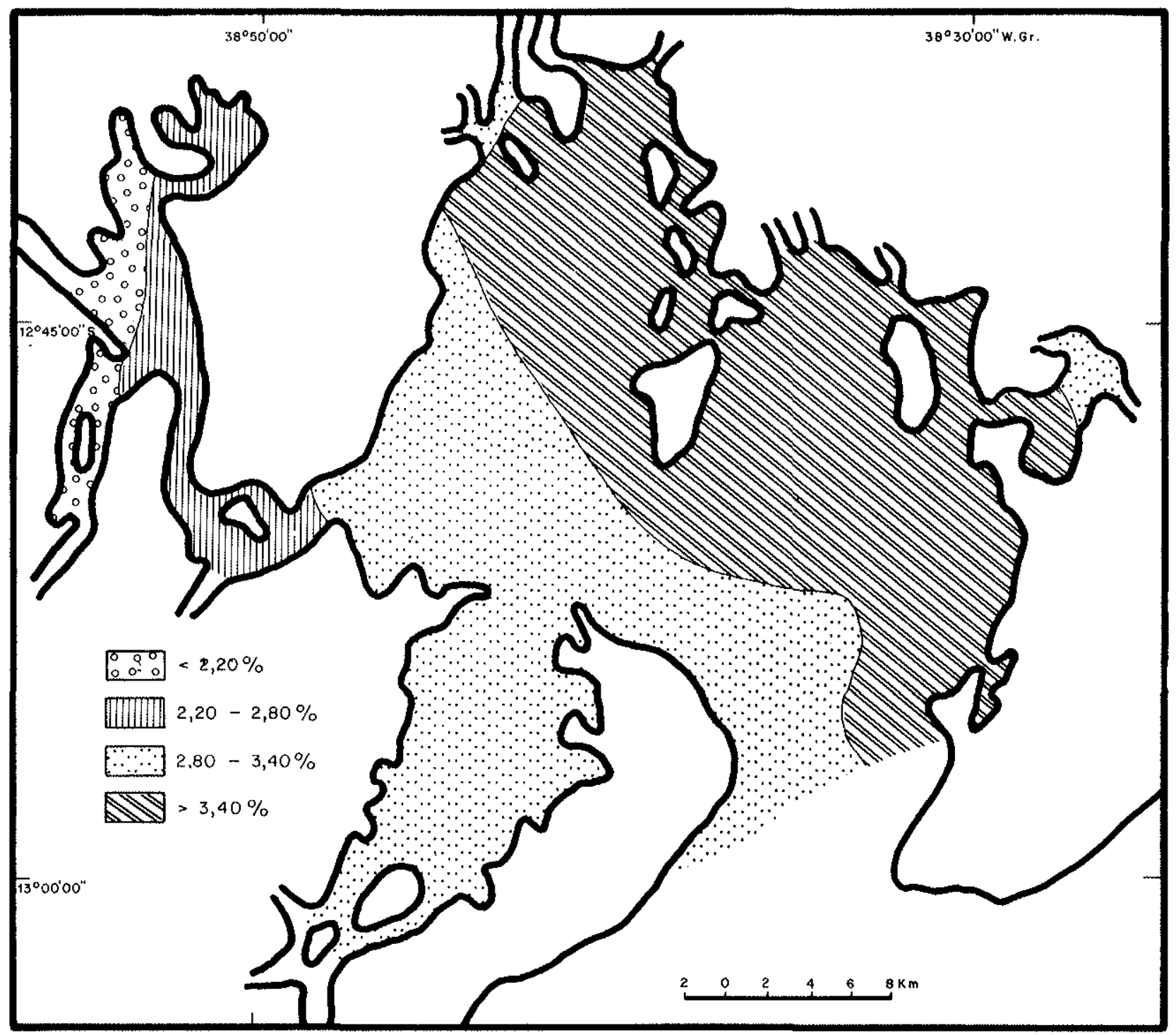

Figura 10 - Mapa de distribuição do $\mathrm{MgO}$

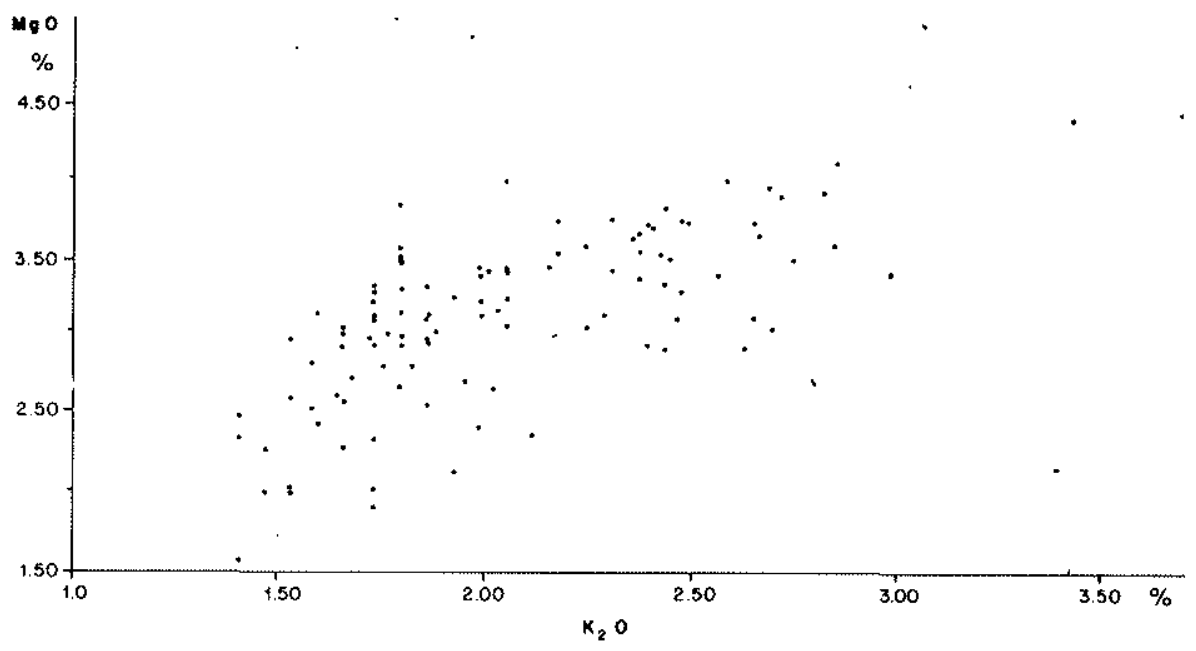

Figura 11 - Relação entre $\mathrm{MgO}$ e $\mathrm{K}_{2} \mathrm{O}$ 
quena parte do ferro esteja associado aos minerais argila, sobretudo montmorillonita e ilita.

Manganês: Os teores de $\mathrm{MnO}$ estão compreendidos entre 0,01 e $0,14 \%$, com valor médio de $0,07 \%$, sendo da mesma ordem de grandeza dos valores médios das rochas argilosas em geral (Krauskopf, 1967).

A correlação com o ferro é pouco significativa, o que não favorece a ocorrência do $\mathrm{Mn}$ associada aos componentes de ferro, na fração argilosa dos sedimentos da Baía de Todos os. Santos. O valor da relação $\mathrm{Mn} / \mathrm{Fe}$ é extremamente baixo, com média de 0,008 . As correlações com as percentagens de caolinita, ilita e montmorillonita bem como com o $\mathrm{K}_{2} \mathrm{O}$ são pouco significativas, sugerindo que o manganês. não está ligado estruturalmente aos minerais de argila, ocorrendo possivelmente disseminado sob forma de óxidos, hidróxidos ou adsorvido na superficie das partículas argilosas.

Titânio: Os teores de $\mathrm{T}_{1} \mathrm{O}_{2}$ variam de 0,66 a $1,22 \%$, com valor médio de $0,91 \%$, que é um pouco elevado em relação ao teor médio de $0,45 \%$ para as rochas argilosas em geral (Krauskopf, 1967).

Goldschmidt (1958) sugere que muito pouco do titânio associado aos minerais de argila é ligado química ou fisicamente aos mesmos, estando provavelmente presente sob forma de dióxido de titânio cristalino ou amorfo, finamente dividido. Nos sedimentos recentes do Golfo de Paria, Hirst (1962) assinala que a maioria do titânio encontrado está ligado a mi: nerais detríticos tais como rutilo, anatásio e brookita. Weaver e Pollard (1973) citam que o titânio é freqüentemente associado com a caolinita e admitem que grande parte do mesmo é adsorvida na superficie desse mineral. Dolcaster et al. (1970) evidenciam a presença do titânio na estrutura da caolinita em posição octaédrica. Wright (1974) considera que o titânio presente na fração argilosa dos sedimentos do mar de Barents (parte oeste da plataforma eurasiana) está presente no interior da estrutura de minerais do tipo ilita, substituindo o ferro e o alumínio.

Na Baía de Todos os Santos a correlação positiva entre $\mathrm{T}_{j} \mathrm{O}_{2}$ e $\mathrm{K}_{2} \mathrm{O}$ indica que a maior parte do titânio presente na fração inferior a $2 \mu$ está ligado estruturalmente a ilita, provavelmente em posição octaedral. É possivel que parte do titânio ocorra sob a forma de óxidos disseminados na fração argilosa, o que explicaria o teor médio relativamente elevado. desse elemento.

Estrôncio: Os teores de $\mathrm{Sr}$ variam de 5 a $89 \mathrm{ppm}$, com média de 27,42 ppm.

O estrôncio é um elemento normalmente presente em esqueletos e fragmentos de organismos (Wolf et $a l ., 1967)$ mas pode também ocorrer adsorvido pelos minerais argila ou no interior da estrutura dos mesmos (Hirst, 1962).
A Fig. 12 mostra a relação entre $\mathrm{Sr}$ e $\mathrm{CaO}$ (coeficiente de correlação de $+0,87$ ) indicando que o estrôncio ocorre juntamente com o cálcio ligado ao material biodetrítico fino presente na fração argilosa.

Cobre: Os teores de Cu variam de 20 a 190 ppm, com média de $52,17 \mathrm{ppm}$, bastante próxima do teor médio de $57 \mathrm{ppm}$ nas rochas argilosas em geral (Krauskopf, 1967). Krauskopf (1956) sugere que o cobre nos sedimentos é efetivamente adsorvido pelos $\mathrm{Fe}(\mathrm{OH})_{3}$ e $\mathrm{Mn}(\mathrm{OH})_{4}$ e pelos minerais argila.

As correlações pouco significativas do $\mathrm{Cu}$ com as percentagens dos diferentes minerais argila sugerem que, na Baía de Todos os Santos, esse elemento não está estruturalmente ligado a esses minerais, ocorrendo provavelmente adsorvido na superficie dos mesmos.

Zinco: Os teores de $\mathrm{Zn}$ variam entre 100 e $840 \mathrm{ppm}$, com média de $141,13 \mathrm{ppm}$, o que é um pouco elevado considerando-se o teor médio de $80 \mathrm{ppm}$ para as rochas argilosas em geral (Krauskopf, 1967). Na maioria das amostras, os teores de Zn são inferiores a $200 \mathrm{ppm}$, sendo que valores mais altos só são encontrados na Baía de Aratu e, sobretudo, na Enseada dos Tainheiros, onde a amostra Z15 apresenta um teor de $840 \mathrm{ppm}$. Esses valores anômalos podem estar relacionados com a poluição por detritos lançados por indústrias existentes nessas áreas.

Cromo e Niquel: Os teores de cromo variam entre 14 e $440 \mathrm{ppm}$, com média dé $78,06 \mathrm{ppm}$. Os teores de níquel estão compreendidos entre 30 e $50 \mathrm{ppm}$, com média de 35,19 ppm. As correlações do $\mathrm{Cr}$ e $\mathrm{Ni}$ com os teores dos diferentes minerais argila são pouco significativas, ocorrendo os mesmos provavelmente adsorvidos na superficie das partículas argilosas.

DISCUSSÃO E CONCLUSÖES Bittencourt et al. (1976) concluíram que a maior parte dos sedimentos finos atualmente introduzidos na Baía de Todos os Santos são trazidos em suspensão pelo Rio Paraguaçu e devem provir em grande parte da desagregação do embasamento cristalino. $O$ material lançado na baía, principalmente durante as cheias; deposita-se preférencialmente na sua metade norte. Ainda segundo os referidos autores, contribuições menores correspondem ao material trazido por pequenos riachos e gamboas, pelo escoamento superficial e pela erosão marginal de folhelhos e siltitos aflorantes notadamente nas costas dos lados norte e leste da baía. A corrente do Brasil penetra na Baía de Todos os Santos transportando para o interior da mesma material fino em suspensão, lançados ao mar pelos rios e riachos da costa atlântica ao norte de Salvador. Evidências da efetividade da ação dessa corrente, são apontadas por Leão (1971), que encontrou carapaças de radiolários e foraminíferos em sedimentos do fundo da parte norte da baía, que teriam sido trazidos de mar aberto. 


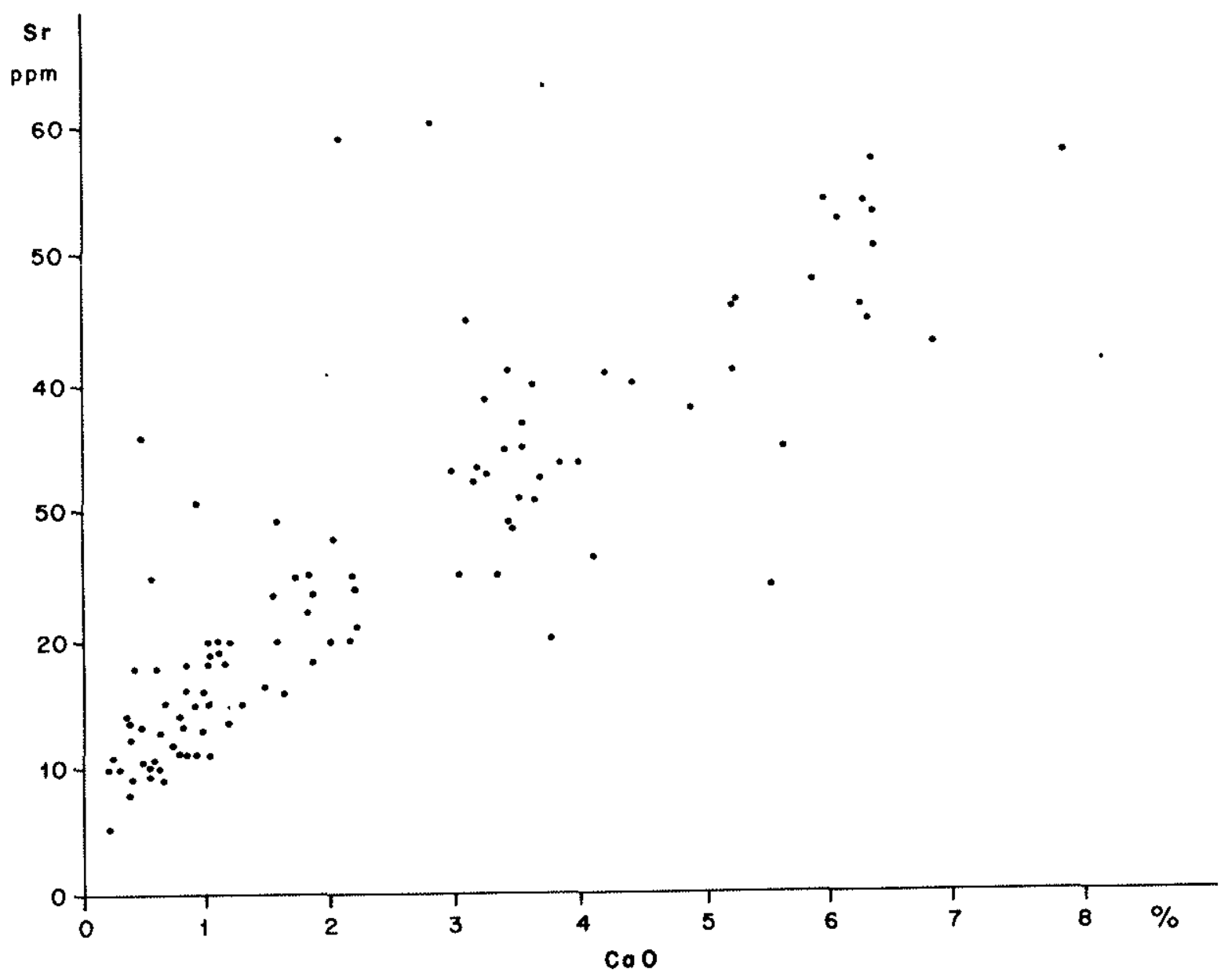

Figura 12 - Relação entre $\mathrm{Sr}$ e $\mathrm{CaO}$

Dois fatores principais devem ser considerados na análise da natureza e distribuição dos minerais-argila no fundo da Baía de Todos os Santos:

1) Clima tropical sempre úmido (Santos, 1962), sem estação seca definida e com pluviosidade anual em torno de $1800 \mathrm{~mm}$, responsável pela intensa alteração química das rochas das regiões circunvizinhas da baía. O mineral argila presente nos solos e produtos de alteração dessa zona é essencialmente a caolinita (Sighinolfi et al., 1973; Fujimori, 1975);

2) Litologia da região em torno da baía, constituída sobretudo de rochas sedimentares do Super Grupo Bahia (Pontes, 1969; Viana et al., 1971). Esses sedimentos são representados nos bordos norte e leste da baía pelas fácies do Cretáceo inferior, constituídas por folhelhos e siltitos cinza esverdeados e arenitos finos. $\mathrm{Na}$ borda ocidental afloram as fácies do Jurássico, representadas por seqüências de camadas avermelhadas constituídas principalmente de arenitos com folhelhos intercalados, que se estendem para oeste até aproximadamente $20 \mathrm{~km}$, em média, sendo limitados pela falha de Maragogipe, limite oeste da bacia do Reconcavo, em contato direto com o embasamento cristalino. Depósitos quaternários afloram esparsamente em alguns trechos (Martin et al. 1978). A caoli- nita, ilita e montmorillonita são respectivamente os minerais argila que predominam nas rochas sedimentares do Super Grupo Bahia (Conceição, 1973; Bahia-sme, 1975).

Desse modo, a composição dos minerais argila, presentes na fração argilosa da Baía de Todos os Santos e cuja característica principal é a predominância da caolinita, reflete basicamente a composição dos solos e rochas da área fonte. No extremo norte, a composição dos minerais de argila é bastante semelhante à das rochas do Super Grupo Bahia aí aflorantes, com predominância de caolinita e ilita em proporções aproximadamente iguais e quantidades subordinadas de montmorillonita. Na metade sul da baía (Fìg. 13), região ainda sob a influência das ondas a correntes oceânicas, a percentagem de caolinita aumenta em detrimento da ilita, o que provavelmente resulta de um aporte de material trazido das zonas oceânicas sobretudo por influência da corrente do Brasil. Esse material, lançado ao mar por rios e riachos da costa oceânica ao norte de Salvador é essencialmente constituído de caolinita (Sighinolfi et al., 1973; Fujimori, 1975). Na Baía de Iguape e na região centro-oeste da Baía de Todos os Santos, zonas de influência do Rio Paraguaçu, o mineral argila 


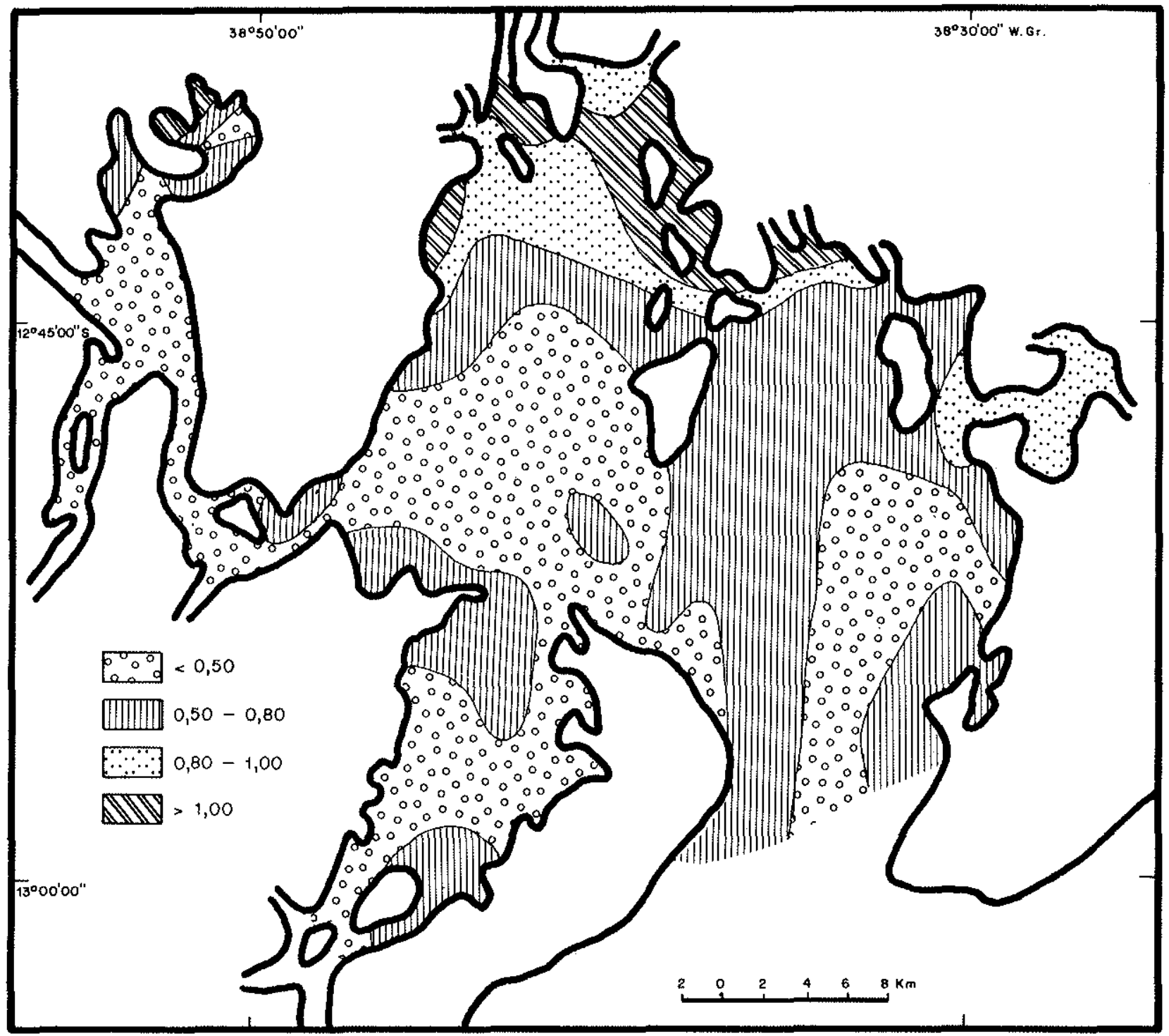

Figura 13 - Mapa de distribuição da relação Ilita/Caolinita

predominante ainda é a caolinita, mas existe uma predominância da montmorillonita sobre a ilita (Fig. 14). O Rio Paraguaçu tem seu curso em grande parte sobre as rochas do embasamento cristalino a oeste da Baía de Todos os Santos. O trabalho de Conceição (1973) sobre os produtos de alteração das rochas do embasamento cristalino do lado ocidental do Recôncavo Baiano, embora limitado a uma região relativamente pequena, mostra que os minerais de argila presentes nos horizontes de alteração são essencialmente a caolinita e a montmorillonita. Por outro lado, P. Laranjeira (informação verbal), estudando os sedimentos em suspensão na desembocadura do Rio Paraguaçu, verificou que os mesmos são constituídos predominantemente da caolinita $\mathrm{e}$ montmorillonita, com quantidades subordinadas de ilita. No interior da Baía de Todos os Santos, ainda segundo $\mathrm{P}$. Laranjeira, à medida que se afasta da zona de influência do Rio Paraguaçu, as relações montmorillonita/ilita e montmorillonita/caolinita diminuem gradativamente, de modo análogo ao que acontece com os sedimentos do fundo (Figs. 14 e 15). Esses fatos mostram que a maior parte da montmorillonita é trazida para o interior da Baía de Todos os Santos pelo Rio Paraguaçu. Na Baía de Iguape, na região frontal à desembocadura do Rio Paraguaçu, as percentagens de caolinita, entre 50 e $60 \%$, são maiores do que nas outras regiões dentro dessa baía, onde as percentagens estão compreendidas entre 40 e $50 \%$. Esse fato é provavelmente devido a uma sedimentação diferencial (Millot, 1964) quando os minerais argilosos trazidos pelo Rio Paraguaçu entram em contato com a água salgada no interior da Baía de Iguape. A caolinita tem uma tendência a sedimentar mais rapidamente que a montmorillonita ao entrar em contato com a água do mar (Whitehouse et al., 1960), o 


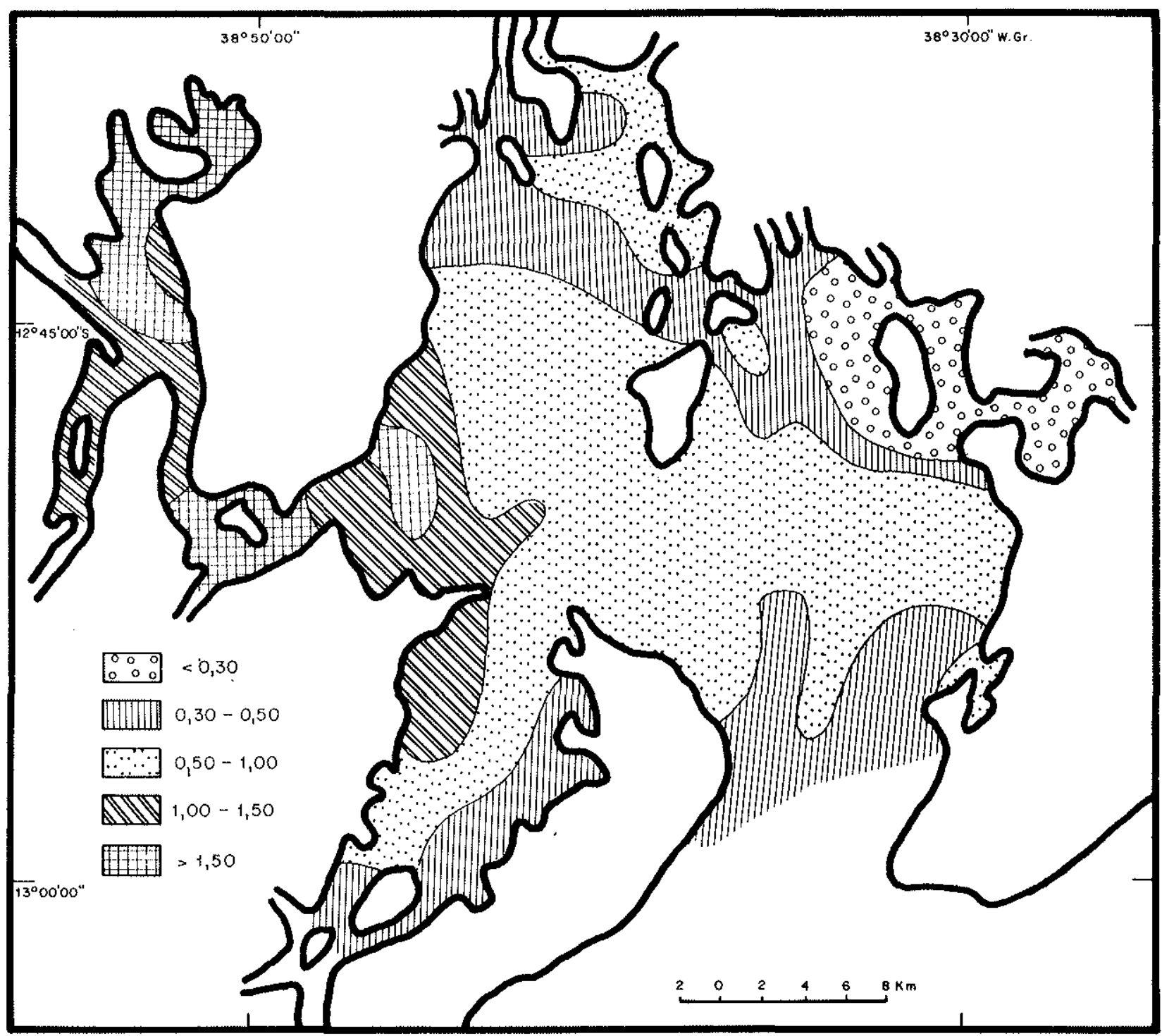

Figura 14 - Mapa de distribuição da relação Montmorillonita/llita

que provoca uma maior concentração deste mineral na zona de desembocadura do Rio Paraguaçu, na Baía de Iguape.

Considerando-se a distribuição dos mineraisargila, a área estudada pode ser dividida em três regiões distintas (Fig. 16):

1) Região norte da Baía de Todos os Santos, de baixa energia, onde a sedimentação argilosa é mais intensa e deriva principalmente da erosão marginal e da desagregação das rochas sedimentares do Super Grupo Bahia. De um modo geral a caolinita domina ligeiramente sobre a ilita enquanto que a montmorillonita aparece em quantidades subordinadas;

2) Região sul da Baía de Todos os Santos, de energia relativamente alta e ainda sujeita a ação das ondas e correntes oceânicas. A sedimentação argìlosa é escassa e em parte influenciada pelo material trazido das regiões oceânicas. A caolinita é franca- mente dominante, com percentagens sempre superiores a $50 \%$ do total de minerais de argila.

3) Região de influência do Rio Paraguaçu, que inclui a Baía de Iguape e zona centro-oeste da Baía de Todos os Santos (região frontal ao canal que a liga à Baía de Iguape), dominada pela sedimentação do do material trazido pelo Rio Paraguaçu. A caolinita é o mineral-argila predominante e a montmorillonita domina francamente sobre a ilita.

A mineralogia e distribuição dos minerais argila controlam em grande parte a distribuição dos elementos maiores tais como $\mathrm{Si}, \mathrm{A} \ell, \mathrm{Mg}$ e $\mathrm{K}$. A razão $\mathrm{S}_{\mathrm{j}} \mathrm{O}_{2} / \mathrm{A}_{\ell_{2}} \mathrm{O}_{3}$, reflete essencialmente a relação entre a proporção de caolinita e a soma das proporções de ilita e montmorillonita. A presença de sílica livre na fração argilosa tende a elevar o valor da razão $\mathrm{S}_{\mathrm{i}} \mathrm{O}_{2}$ $\mathrm{A}_{\ell} \mathrm{O}_{3}$. As distribuições do potássio e magnésio estão associados essencialmente a distribuição da 


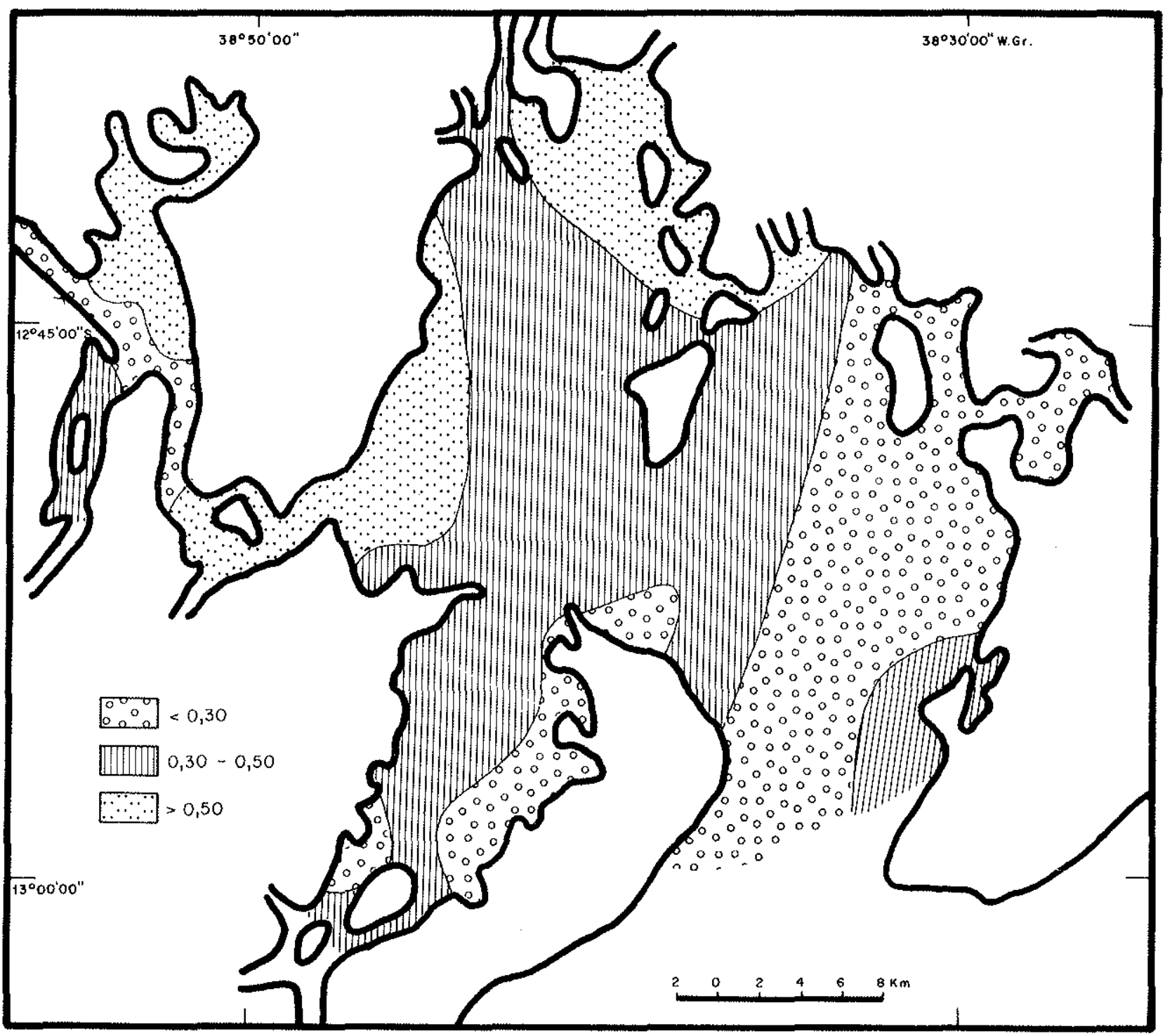

Figura 15 - Mapa de distribuição da relação Montmorillonita/Caolinita

ilita. Os teores mais altos desses elementos ocorrem a norte e nordeste da Baía de Todos os Santos, onde as percentagens de ilita são mais elevadas, e são da mesma ordem dos teores observados nas rochas argilosas do Super Grupo Bahia (Shiguemi Fujimori, informação verbal) que são a principal fonte dos sedimentos argilosos que se depositam nessa parte da baía. As distribuições do cálcio e estrôncio estão ligadas à presença de material biodetrítico fino constituído de calcita, que ocorre na fração argilosa. A ação do intemperismo quimico sobre as rochas da região circunvizinha à báa, é provavelmente o mecanismo mais efetivo controlando a origem do ferro associado aos sedimentos argilosos do fundo da Baía de Todos os Santos. A mobilização do ferro durante a alteração é evocada por Degens (1965), sendo que o mesmo pode ser transportado associado aos minerais argilosos (Carroll, 1958) ou em solução
(Degens, 1965: Krauskopf, 1967). Quando associado com os minerais argilosos o ferro pode estar presente no interior da estrutura ou aderido à superficie das partículas argilosas sob a forma de óxidos tais como, goethita, lepidocrocita, hematita ou óxidos indefinidos de baixa cristalinidade (Carroll, 1958). No caso do transporte em solução, a dissolução do ferro é acelerada em condiçòes de clima úmido e quente com vegetação abundante, de modo que as condições de pH e Eh das águas superficiais e sub-superficiais sejam baixas. A precipitação do ferro a partir de tais soluções pode ser realizada em uma bacia restrita ou braço de mar, onde o efeito das ondas e correntes é pequeno (Krauskopf, 1967). Na Baía de Todos os Santos é provável que a maioria do ferro tenha sido transportado para o interior da mesma tanto sob a forma de óxidos associados as partículas argilosas, como em solução. No caso do transporte em solução, a preci- 


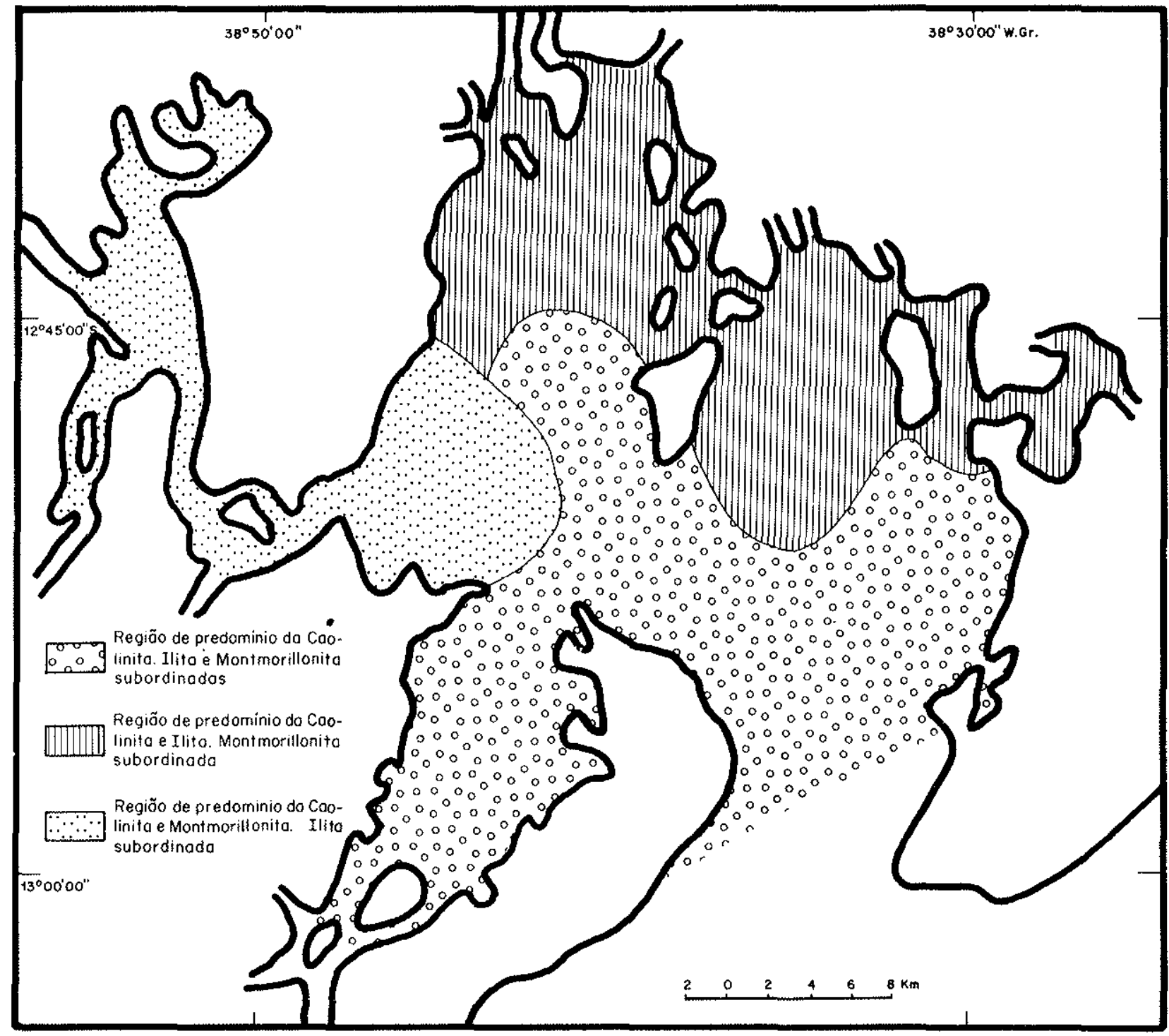

Figura 16 - Mapa de distribuição das Fácies Argilosas

pitação do ferro é favorecida pelas condições ambientais de relativa restrição e baixa energia. $O$ trabalho de Sighinolfi et al. (1973) mostra que durante a alteração das rochas do embasamento cristalino da região de Salvador existe uma separacão efetiva do ferro e manganês. Esse mecanismo é provavelmente responsável pelo valor extremamente baixo da relação $\mathrm{Mn} / \mathrm{Fe}$ dos sedimentos argilosos do fundo da baía. Os elementos tais como o cobre, cromo, níquel e zinco ocorrem sobretudo adsorvidos na superficie das partículas argilosas. No caso do zinco, concentrações anômalas muito acima do valor médio regional estão ligadas a poluição dos sedimentos por detritos industriais.

Agradecimentos Os autores deixam aqui expressos os seus agradecimentos, através do Programa de Pesquisa e Pós-Graduação em Geofisica da UFBa, às entidades financiadoras, FINEP e CNPq. Agradecimentos são extensivos aos Profs. Shiguemi Fujimori, Yeda A. Ferreira e Edson E. Sampaio, pelas críticas e sugestões apresentadas. 


\section{BIBLIOGRAFIA}

ANDREA, R., 1962, Chuvas na Bahia, DNOCS-CPE, Salvador, BA.

AVANZO, P. E., 1977, A sedimentação no setor central da baía de Maragogipe. Tese de Mestrato em Geologia/Sedimentologia. Univ. Fed. Bahia (inédito).

BAHIA, SECRETARIA DAS MINAS E ENERGIA. COORDENAÇÃO DA PRODUCÃO MINERAL, 1975, Projeto argila no Recôncavo Baiano; Relatório Final, V. 1 (texto), $160 \mathrm{pp}$.

BISCAYE, P. E., 1965, Mineralogy and Sedimentation of Recent Deep-Sea clay in the Atlantic Ocean and Adjacent Seas and Oceans, Geol. Soc. Am. Bull., 76(7): 803-832.

BITTENCOURT, A. C. S. P., FERREIRA, Y. A. e DI NAPOLI, E., 1976, Alguns aspectos da sedimentação recente na Baía de Todos os Santos, Bahia, Rev. Bras. Geoc., 6(4) : 243-263.

BITTENCOURT, A. C. S. P. e VILAS BOAS, G. S., 1977, Ocorrência de chamosita nos sedimentos recentes da baía de Aratu (BA), Rev. Bras. Geoc., 7(3): 230-238.

BRICHTA, A., 1977, A sedimentação na Foz do Rio Paraguaçu, BA. Tese de Mestrado em Geologia/Sedimentologia, Univ. Fed. Bahia (inédito).

CARROLL, D., 1958, Role of clay minerals in transportation of iron, Geochim. Cosmochim. Acta, 14(1/2): 1-27.

CONCEIÇÃO, T. M. L., 1973, Alteração de rochas e sedimentos da parte ocidental do Recôncavo Baiano. Tese Professor Assistente. Univ. Fed. Bahia (inédito).

DEGENS, E. T., 1965, Geochemistry of Sediments, Prentice Hall, New Jersey, N. J., 342 pp.

DOLCASTER, D. L., SYERS, J. K. e JACKSON, M. L., 1970, Titanium as free oxide and substituted forms in kaolinite and other soil minerals, Clays Clay Miner. 18 (2): 71-79.

FUJIMORI, S., 1975, Haloisita no embasamento cristalino alterado de Salvador (BA), Rev. Bras. Geoc., $5(4): 267-273$.

GOLDSCHMIDT, V. M., 1958, Geochemistry. Oxford Univ. Press, London, 730 pp.

HIRST, D. M., 1962, The geochemistry of modern sediments from de Gulf of Paria-I. The relationship between the mineralogy and the distribution of major elements., Geochim. Cosmochim. Acta 26 (2): 309-334.

KRAUSKOPF, K. B., 1956, Factors controlling the concentration of thirteen rare metals in sea water., Geochim. Cosmochim. Acta, 9(1/2): 1-33B.

KRAUSKOPF, K. B., 1967, Introduction to geochemistry. McGraw Hill, New York, 721 pp.

LEÃO, Z. M. A. N., 1971, O depósito conchifero da Laje de Ipeba, BA., Tese de mestrado em Geociências. Univ. Fed. Bahia (inédito).

MACEDO, M. H. F., 1977, Estudo sedimentológico da Baía de Todos os Santos. Tese de mestrado em Geologia/Sedimentologia. Univ. Fed. Bahia (inédito).

MALDEN, P. J. e MEADS, R. E., 1967, The solid state. Nature: 215: 844-845.

MARTIN, L., BITTENCOURT, A. C. S. P., VILAS BOAS, G. S. e FLEXOR, J. M., 1978, Introdução ao estudo do Quaternário no litoral do Estado da Bahia - Trecho SalvadorIlhéus. Rev. Bras. Geoc. (no prelo).

MILlOT, G., 1964, Geologie des Argiles. Masson, Paris, 499 pp.

OINUMA, K., KOBAYASH,, K. e SUDO, T., 1959, Clay mineral composition of recent sediments., Jour. Sed. Pet, 29 (1): 56-63.

PONTES, A. R., 1969, Excursão às bacias sedimentares do Recôncavo e Tucano Sul. XXIlI Congr. Bras. Geol., Roteiro das Excursões, pp. 32-41. Salvador, BA.

ROBERTSON, R. H. S., BLINDLEY, G. W. e MACKENZIE, R. C., 1954, Mineralogy of Kaolin clays from Puger, Tanganiyika. Am. Mineral. 39 (1/2): 118-138.

SANTOS, R. A. F., 1962, Chuvas na Bahia. Salvador, BA, DNOCS/CPE, $170 \mathrm{pp}$

SIGHNOLFI, G. P., AZEVEDO, L. S. P., LINHARES, P. S., e MONIZ, A. C., 1973, Mineralogical and chemical variations induced by tropical weathering of granulitic rocks from the brazilian basement, Rev. Bras. Geoc., 3(2): 71-83.

VIANA, C. F.; GAMA Jr., E. G.; SIMÖES, I. A.; MOURA, J. A.; FONSECA, J. R. e ALVES, R. J., 1971, Revisão Estratigráfica da Bacia do Recôncavo-Tucano. Bol. Técnico da Petrobrás. R. de Janeiro, $14(3 / 4): 157-192$.

WEAVER, C. E. e POLLARD, L., 1973, The chemistry of clay minerals, Elsevier Scientific Publishing Company, Amsterdam, 213 pp.

WHITEHOUSE, U. G., JEFFREY, L. M., DEBRECHT, J. D., 1960, Differential settling tendencies of clay minerals in saline waters. Clays and clay minerals (7th Nat. Conf., 1958), pp. $1-80$.

WOLF, K. H.; CHILINGAR, G. V. e BEALES, F. W., 1967, Elemental composition of carbonate skeletons, minerals, and sediments, pp. 23-149, in CHILINGAR, G. V., BISSELL, H. J. e FAIRBRIDGE, R. W. ed., Carbonate Rocks, V. 1. Elsevier Publishing Company, Amsterdam, $413 \mathrm{pp}$.

WRIGHT, P. L., 1974, The chemistry and mineralogy of the clay fraction of sediments from the southern Barents Sea, Chem. Geol., 13(3): 197-216. 